\title{
Vertical profiles of urban aerosol complex refractive index in the frame of ESQUIF airborne measurements
}

\author{
J.-C. Raut and P. Chazette \\ Laboratoire des Sciences du Climat et de l'Environnement, Laboratoire mixte CEA-CNRS-UVSQ, CEA Saclay, 91191 \\ Gif-sur-Yvette, France
}

Received: 7 June 2007 - Published in Atmos. Chem. Phys. Discuss.: 25 July 2007

Revised: 22 November 2007 - Accepted: 18 January 2008 - Published: 22 February 2008

\begin{abstract}
A synergy between lidar, sunphotometer and in situ measurements has been applied to airborne observations performed during the Etude et Simulation de la QUalité de l'air en Ile-de-France (ESQUIF), enabling the retrieval of vertical profiles for the aerosol complex refractive index (ACRI) and single-scattering albedo with a vertical resolution of $200 \mathrm{~m}$ over Paris area. The averaged value over the entire planetary boundary layer (PBL) for the ACRI is close to $1.51( \pm 0.02)-\mathrm{i} 0.017( \pm 0.003)$ at $532 \mathrm{~nm}$. The singlescattering albedo of the corresponding aerosols is found to be $\sim 0.9$ at the same wavelength. A good agreement is found with previous studies for urban aerosols. A comparison of vertical profiles of ACRI with simulations combining in situ measurements and relative humidity (RH) profiles has highlighted a modification in aerosol optical properties linked to their history and the origin of the air mass. The determination of ACRI in the atmospheric column enabled to retrieve vertical profiles of extinction coefficient in accordance with lidar profiles measurements.
\end{abstract}

\section{Introduction}

A variety of processes can lead to the production of atmospheric particles. They may arise from natural sources such as sea-spray, desert dust storms and volcanic activity, and also from anthropogenic sources such as fossil fuels combustion and biomass burning activities (e.g. Lenoble, 1993; Liousse et al., 1995; Tegen and Fung, 1995), and from gas-toparticles conversion processes (Pandis et al., 1995). Among all the numerous sources of anthropogenic particles, the pollutant aerosols emitted in large urban areas, and mainly consisting of sulfate, nitrate, black carbon and particulate organic matter, are now clearly recognized as one of the most important. They modify the local or regional climate when

Correspondence to: J.-C. Raut

(jean-christophe.raut@cea.fr) pollutants are transported out of the source regions into surrounding areas: these pollutants indeed influence the albedo of the atmosphere - surface system and can interact with clouds (Pruppacher and Klett, 1997).

The high variability of physical and optical properties of particles linked to meteorological parameters such as temperature, humidity and wind speed require studying aerosols in their natural state. Over the past several years, aerosol features have been intensively investigated through numerical modelling (Braslau and Dave, 1973; Hodzic et al., 2006) and thanks to experiments (e.g. Zobel, 1966; Method and Carlson, 1982; Haywood, 2003). Detailed information on aerosol physical and optical properties can be provided by surface-based in situ measurements but those observations often remain limited to the ground. Aerosol properties can however be measured by aircraft instruments. Dubovik et al. (2000) also ascertain aerosol features by intensively measuring solar transmission and sky radiation. But results of such passive measurements are averaged over the entire atmospheric column and cannot provide information regarding the vertical distribution of particles. In this way, remote sensing approaches turn out to be a well appropriate and complementary tool in the determination of particle optical properties (e.g. Chazette, 2003). Fuller and more accurate studies are required because these aerosols play a critical role in the atmospheric energy budget and have long-term effect on the climatic changes (Charlson and Pilat, 1969).

The study presented in this paper underlines the ability of the combination between aerosol size distribution and scattering cross-section measured by a french research aircraft to determine vertical profiles of aerosol complex refractive index (ACRI), a crucial parameter driving optical properties and highly dependent on chemical composition of the particles. Retrievals of ACRI vertical profiles are indeed scarce. Ferrare et al. (1998) measured both aerosol extinction and backscattering as a function of altitude thanks to a Raman lidar to infer real ACRI, single-scattering albedo and

Published by Copernicus Publications on behalf of the European Geosciences Union. 
humidity correction factors of tropospheric aerosols in Oklahoma in conjunction with aerosol size distribution. Multiwavelength backscatter and extinction lidar measurements also enable to retrieve vertical profiles of ACRI. A detailed description of such an inversion scheme has been given by Müller et al. (1999) and applied to pollution plumes advected from the European continent out over the Atlantic Ocean (Müller et al., 2002) giving profiles split into layers of variable depth from 400 to $700 \mathrm{~m}$ or over an Indian aerosol plume (Wagner et al., 2001). Redemann et al. (2000) combined lidar, sun photometer and particle sizers data to retrieve both real and imaginary parts in the atmospheric column over Atlantic Ocean that would provide the same backscatter signal in a forward calculation. Without the knowledge of scattering coefficients, they solved this ill-posed problem by assuming a constant ACRI over a certain vertical distance associated with various sets of measurements for size distribution and lidar within the same atmospheric portion. Redemann et al. (2000) minimized the relative difference of scattering ratios from lidar and from calculation using a grid of discrete values both in the real and in the imaginary parts. That led to only two complex refractive indices in the boundary layer: one on the surface layer and the other one representative on a boundary-type layer. The main limitation of this method is to find a minimum of a function of two variables on a finite grid since the grid itself can introduce errors in the retrieved ACRI.

In this study, ACRI retrieval has been performed in the framework of the Etude et Simulation de la QUalité de l'air en Ile-de-France (ESQUIF) experiment that took place over the Paris area in July 2000, involving airborne measurements (Chazette et al., 2005). Next we relate the variations in the retrieved ACRI to the meteorological conditions during the experiment and discuss their evolution in the atmospheric column by looking at their past and the origin of the air masses. We finally show how extinction profiles can be simulated to closely reproduce the lidar signals in ambient conditions.

\section{Experimental setup}

\subsection{Instruments}

The french research aircraft Fokker27/ARAT (Avion de Recherche Atmosphérique et de Télédétection) was used during the ESQUIF program in July 2000 for in situ and remote sensing measurements within the lower troposphere. The aircraft instrumentation included the lidar LEANDRE-1 (Lidar aéroporté pour l'Etude des Aérosols, des Nuages, de la Dynamique, du Rayonnement et du cycle de l'Eau) to document the atmospheric reflectivity at 532 and $1064 \mathrm{~nm}$ in the lower troposphere. LEANDRE 1 uses sub-micron aerosols as tracers to document the lower tropospheric structure with a vertical resolution of $15 \mathrm{~m}$ (Pelon et al., 2002). The mean relative error for the extinction coefficient is generally less than $10 \%$ when the inversion of lidar profiles is constrained using a sunphotometer (Chazette, 2003) and when the relative humidity (RH) stays lower than $75 \%$, as is the case here. The airborne optical particle sizer PCASP model 100, developed by Particle Measuring Systems (PMS Inc, Boulder, Co), gives access to 15 classes of particles ranging from $>0.1$ up to $>3 \mu \mathrm{m}$ in diameter. It is used to retrieve the aerosol number size distribution in the lower troposphere. The accuracy on the aerosol number concentration measurement is about 5\% for submicron aerosols (Dye and Baumgardner, 1984). The size distribution retrieved from this instrument does not necessarily represent that at ambient conditions. By comparing the PCASP aerosol size measurements with those measured by a forward scattering spectrometer probe instrument that did not dry the aerosols, Strapp et al. (1992) pointed out that the particles appear to be dried by the PCASP heating before measurement at all RH up to $80-90 \%$, i.e. in all cases considered in this study. Number concentrations of submicron particles were measured with $3022 \mathrm{~A}$ CPC TSI ${ }^{\circledR}$ model particle counters. These counters detect all particles within a diameter size range from 0.007 to $3 \mu \mathrm{m}$, with a $100 \%$ efficiency for $0.02 \mu \mathrm{m}$. Particle concentrations are retrieved with a relative uncertainty of $5 \%$ (Chazette and Liousse, 2001). A three-wavelength (450, 550 and $700 \mathrm{~nm})$ nephelometer (manufactured by $\mathrm{TSI}^{\circledR}$ ) was used onboard the aircraft. This instrument measures the aerosol scattering coefficient in a $7-170^{\circ}$ range of scattering angle (e.g. Bodhaine et al., 1991; Flamant et al., 2000). To take into account the non-observed scattering angles, a correction factor has been assessed, from Mie computations, to be close to 1.035 for urban aerosols (Chazette et al., 2005). This assessment was done using the retrieved aerosol mean size number distribution and the mean complex refractive index during July 2000. Such a small value for the correction factor can be explained by the predominant very small particles in the size distribution (Table 1) since these latter do not clearly modify the phase function in the small scattering angles. The instrument scattering chamber was maintained at about 35-40\% RH (dry aerosol conditions). In dry conditions, the relative uncertainty after calibration is around a few per cent (evaluated from the reproducibility of laboratory measurements).

Optical thickness data of the Paris area were obtained from the AErosol RObotic NETwork (AERONET): the channels of the sunphotometer used for this study are centered at $(440 \mathrm{~nm}$ and $670 \mathrm{~nm})$ or $(438 \mathrm{~nm}$ and $669 \mathrm{~nm})$ given the location of the site, with bandwidths of less than $20 \mathrm{~nm}$ and the instrument field of view is about $1^{\circ}$ (Holben et al., 1998). The AERONET database gives a maximal absolute uncertainty of 0.02 for the optical thickness, independent of the aerosol loading. AERONET website indeed suggests an uncertainty of 0.01-0.02 in aerosol optical thickness, that is wavelength dependent, due to calibration uncertainty for the field instruments (http://aeronet.gsfc.nasa.gov/new_web/ system_descriptions_calibration.html). 
Table 1. Mean aerosol size number distribution characteristics derived from aircraft on 19, 20 and 31 July 2000 during ESQUIF program. A lognormal size distribution is assumed, which is characterized by up to three modal radii $\left(r_{1}\right.$ and $\left.r_{2}\right)$, the associated geometric dispersions $\left(\sigma_{1}\right.$ and $\left.\sigma_{2}\right)$, and occupation rates $\left(x_{1}\right.$ and $\left.x_{2}=1-x_{1}\right)$. The temporal variability is given in parenthesis. The uncertainties due to the retrieval procedure are also specified.

\begin{tabular}{lllllll}
\hline Date & & $r_{1}(\mu \mathrm{m})$ & $\sigma_{1}$ & $r_{2}(\mu \mathrm{m})$ & $\sigma_{2}$ & $x_{1}(\%)$ \\
\hline $19 / 07 / 2000$ & Part 1 & 0.042 & 1.363 & 0.112 & 1.326 & 73.8 \\
& & $( \pm 0.008)$ & $( \pm 0.196)$ & $( \pm 0.012)$ & $( \pm 0.160)$ & $( \pm 9.2)$ \\
$19 / 07 / 2000$ & Part 2 & 0.039 & 1.543 & 0.120 & 1.231 & 72.2 \\
& & $( \pm 0.003)$ & $( \pm 0.083)$ & $( \pm 0.004)$ & $( \pm 0.030)$ & $( \pm 3.0)$ \\
$20 / 07 / 2000$ & & 0.040 & 1.585 & 0.119 & 1.222 & 71.2 \\
& & $( \pm 0.006)$ & $( \pm 0.182)$ & $( \pm 0.006)$ & $( \pm 0.042)$ & $( \pm 4.5)$ \\
$31 / 07 / 2000$ & \multirow{2}{*}{ Part 1 } & 0.031 & 1.486 & 0.118 & 1.302 & 81.7 \\
& & $( \pm 0.004)$ & $( \pm 0.049)$ & $( \pm 0.008)$ & $( \pm 0.091)$ & $( \pm 4.2)$ \\
$31 / 07 / 2000$ & \multirow{2}{*}{ Part 2 } & 0.034 & 1.496 & 0.119 & 1.257 & 81.4 \\
& & $( \pm 0.003)$ & $( \pm 0.053)$ & $( \pm 0.007)$ & $( \pm 0.069)$ & $( \pm 3.2)$ \\
\multicolumn{2}{l}{$\begin{array}{l}\text { Uncertainties from } \\
\text { Monte-Carlo method }\end{array}$} & 0.01 & 0.01 & 0.015 & 0.02 & 3 \\
\end{tabular}

The uncertainty on the aerosol optical thickness at the considered wavelength ( $532 \mathrm{~nm}$ in this paper) can be calculated from maximal absolute uncertainty (0.02) and errors on the Angström exponent.

Aerosol chemical composition was also analyzed from sampling performed at the ground level. Aerosol samples devoted to carbonaceous analyses were collected during 19 and 20 July, 2000, with low volume sampler $\left(3 \mathrm{~m}^{3} \mathrm{~h}^{-1}\right)$ on precleaned Whatman GF/F glass-fibber filters. The carbon mass was determined through a thermal protocol. The precision of the results is estimated to be of the order of $10 \%$. Nuclepore membranes were also mounted on stack filters unit in order to separate the coarse and the fine fraction of the inorganic water soluble (WS) fraction of the aerosols, without sea-salts. These filters were used for measuring the major soluble inorganic ions in the particle by ion chromatography. The precision on ion chromatography analysis has been evaluated to be $5-10 \%$ (Randriamiarisoa, 2006).

\subsection{Flight plans}

Flight plans were established according to the daily synoptic conditions and Planetary Boundary Layer (PBL) depths using ECMWF (European Center for Medium-range Weather Forecast) forecasts and the flight altitudes imposed by Air Traffic Control. Flight plans for 19 and 31 July are fully described in Chazette et al. (2005) and shown in Fig. 1a and e, together with the raw aerosol scattering coefficient measured by the airborne nephelometer, as well as the corresponding vertical profiles of RH. The scattering coefficient evolution illustrates the location of the pollution plume around Paris. The flight plan for 20 July has been also taken into account and shown in Fig. 1c.
The major difference between the two periods was the direction of the air flow. We computed two-day backtrajectories of air masses arriving at $500 \mathrm{~m}$ above mean sea level (m.s.l.) in the mixed layer (red), $1500 \mathrm{~mm}$.s.l. close to the top of the PBL (blue), $2500 \mathrm{~mm}$.s.l. in the free troposphere (green) at Paris using the Hysplit model (courtesy of NOAA Air Resources Laboratory; http://www.arl.noaa. gov). This model uses the meteorological data to compute advection and dispersion of air parcels. Figure 2 shows these trajectories for air parcels arriving over Paris area at 12:00 UT on the days listed. Whereas the trajectories ending at $500 \mathrm{~m}$ m.s.l. spent time near the surface, the trajectories at 1.5 and $2.5 \mathrm{~km}$ remained almost constant in altitude. We can however notice that back trajectories in the PBL are suspect. We therefore performed a sensitivity study on the back trajectories from Hysplit. That study was conducted considering a set of end points surrounding the exact location of Paris $\left(48.85^{\circ} \mathrm{N}, 2.33^{\circ} \mathrm{E}\right)$. The corresponding locations belong to the range $\left[48.55^{\circ} \mathrm{N}-49.05^{\circ} \mathrm{N}\right]$ and $\left[2.23^{\circ} \mathrm{E}-2.43^{\circ} \mathrm{E}\right]$. This is particularly crucial in the lowest altitudes. In our case $(500 \mathrm{~m})$, we did not observed any influence of the multiple trajectories in altitude. It guarantees the lack of sensitivity of the precise location of the end point. One has to note that Hysplit model is working at a large scale that does not cover turbulent mixing processes. The several depositions on the surface along the way of the backtrajectories arriving at $500 \mathrm{~m}$ have not any physical significance. But they simply suggest that the air mass at this altitude level may stay in the PBL.

To better sample the urban pollution production, crosswind flight legs were performed within the PBL. Calculations performed in this study following the altitude stem only from ascending phases of the flights since important bias on in situ measurements are observed during descending phases. 
(a)

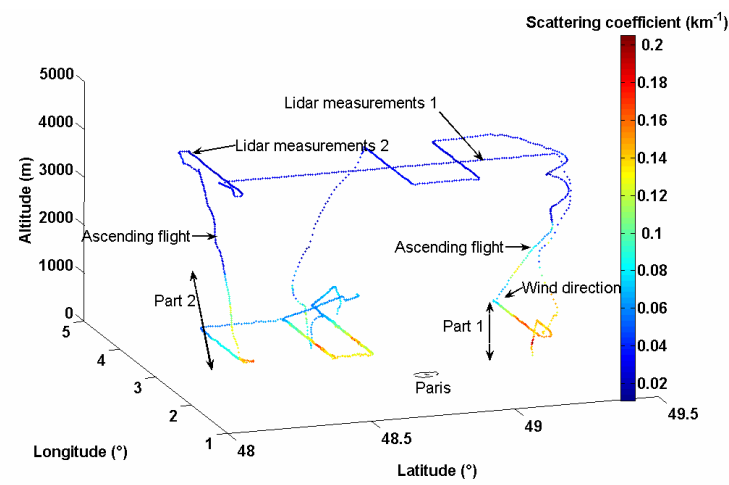

(c)

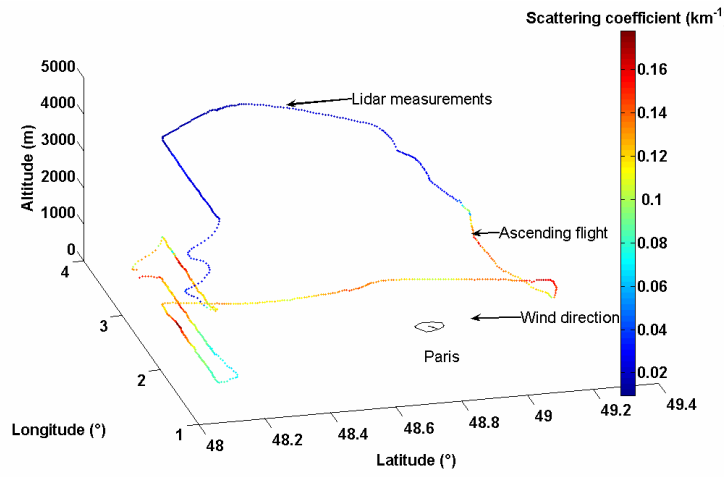

(e)

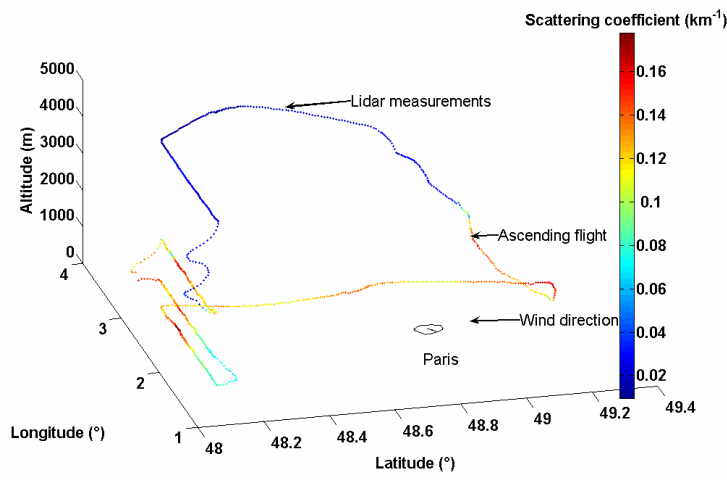

(b)

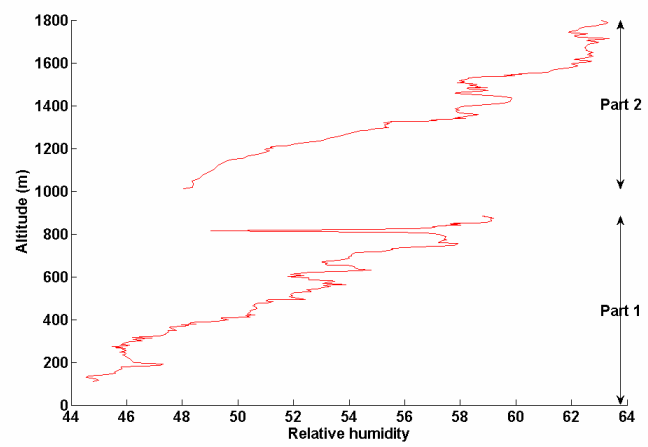

(d)

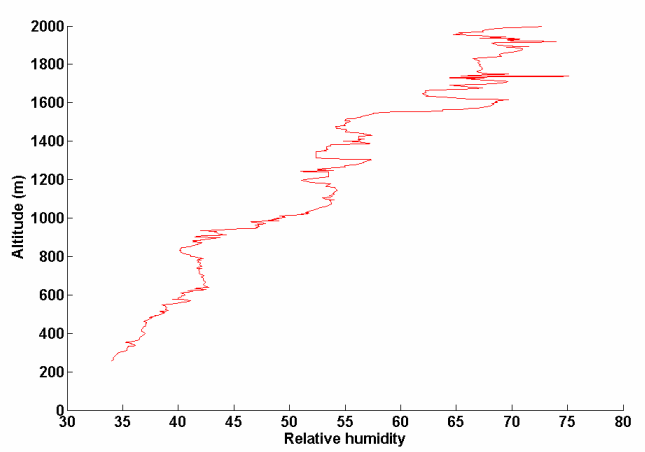

(f)

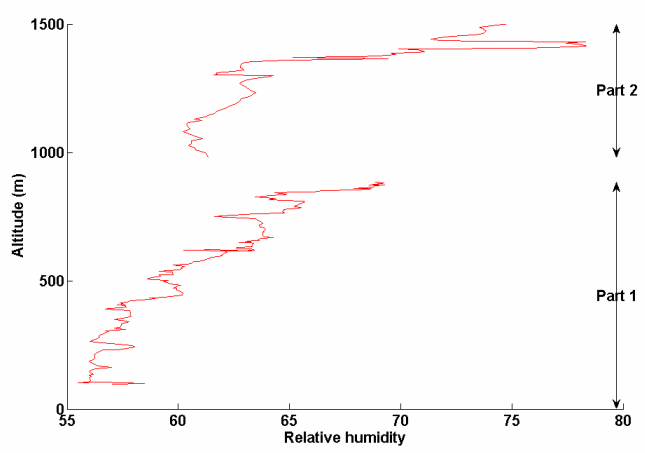

Fig. 1. Flight plans (a, c and e) and vertical profiles of RH (b, d and f) over Paris area measured during the ascent on 19 (a, b), 20 (c, d) and 31 (e, f) July 2000 respectively. The scattering coefficient measured onboard the aircraft is color coded. The separation of the vertical profiles in two parts (Part 1 and Part 2) is related to a discontinuity associated with horizontal explorations.

The flow rate, for each instrument sampling line, has been controlled during the ascending phases to ensure flow conditions as close as possible to isokinetism. Isokinetic problems involved in aerosol measurements have been minimized during ascending flights.

On 19 July, under northerly wind conditions, two flights were performed at 10:40-13:30 UTC and 14:20-17:15 UTC. The incoming air mass originating from Great Britain was already rich in aged aerosol indicating that the air mass had flown over polluted areas prior to reaching the Paris area (Chazette et al., 2005). Two parts corresponding to upwind and downwind sides of Paris can be distinguished for com- putations. The first part (Part 1) starts from Creil with a low level upwind leg. The second part (Part 2) begins with a leg further south over the countryside before climbing at $\sim 4200 \mathrm{~m}$ m.s.l. Lidar measurements were realized on a first crosswind leg coinciding with Part 2, and then a south-north segment toward Creil coinciding with Part 1. According to backscatter lidar profiles, the mean PBL depth was about $1800 \pm 100 \mathrm{~m}$ during the considered flight period. The retrieved optical thicknesses at $532 \mathrm{~nm}$ were $0.25 \pm 0.03$ before 10:30 UTC and 0.3 \pm 0.05 before 12:00 UTC above Palaiseau (south of Paris) and Paris AERONET stations respectively. The corresponding values are given with an errorbar higher 
(a)

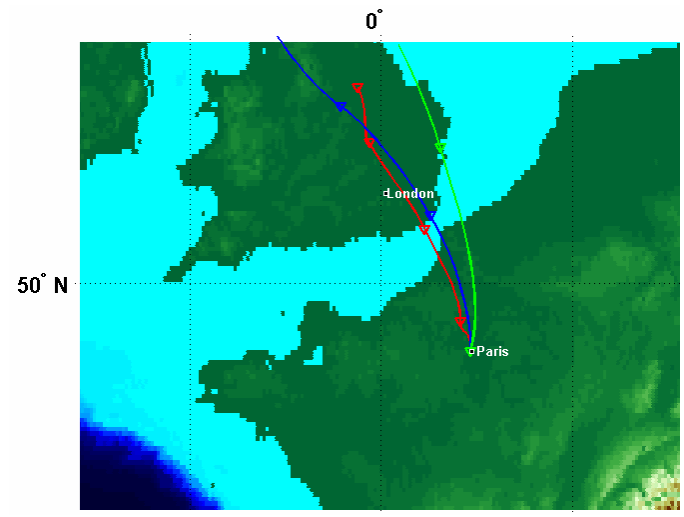

(c)

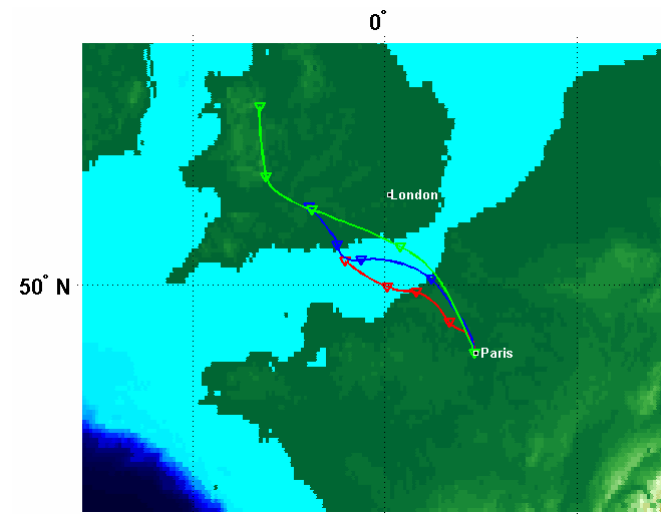

(e)

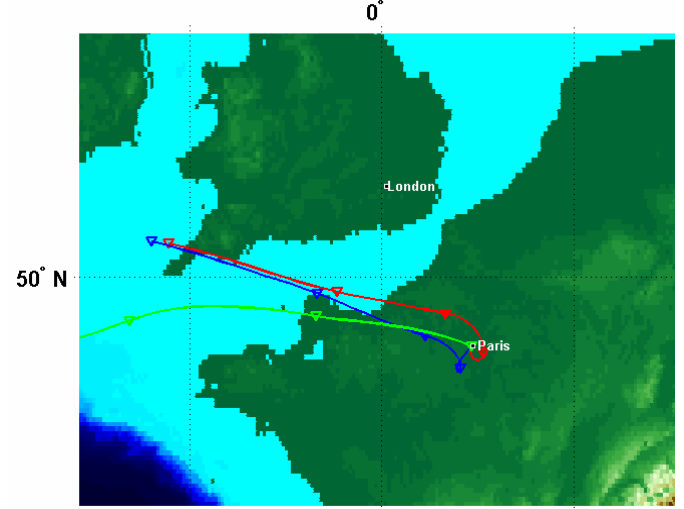

(b)

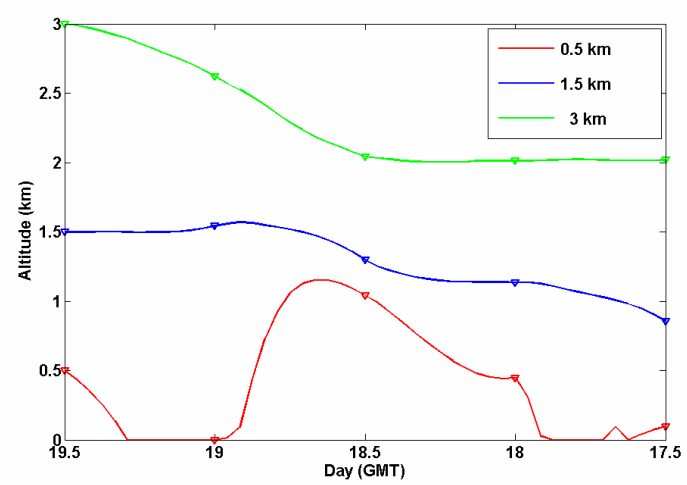

(d)

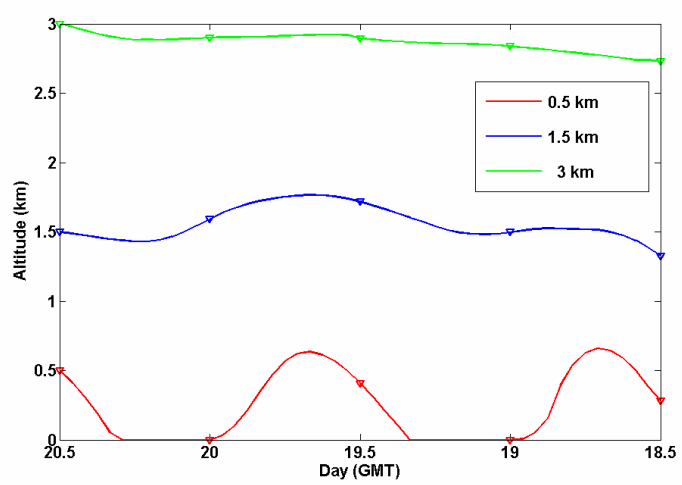

(f)

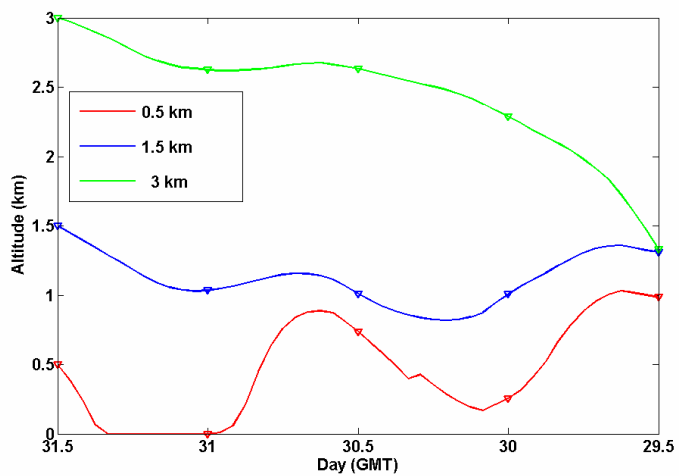

Fig. 2. Back trajectories for three 2-day periods ending over Paris at 12:00 UTC on (a) 19 July, (c) 20 July and (e) 31 July at 0.5 , 1.5, and $2.5 \mathrm{~km}$ m.s.l. (courtesy of NOAA Air Resources Laboratory http://www.arl.noaa.gov). The triangles give the 12-h spacing. The location of the air mass for each day against the altitude is given in (b), (d) and (f), respectively.

than 0.02 because the calculation of the uncertainty has been realized at $532 \mathrm{~nm}$, which takes into account the errors on aerosol optical thicknesses (0.02) and on Angström exponent. After these hours, no other reliable optical thicknesses data were available due to increased cloudiness.

On 20 July, the flight was scheduled between 14:00 and 17:45 UTC. It was dedicated to the study of vertical exchanges in the low troposphere inside Paris pollutant plume. The incoming air mass is carried by a north airflow which is probably already polluted, but with a more urban pollu- tion component (Cardiff, Bristol). In situ measurements are realized during the ascending flight, upwind of Paris. Nadir pointing lidar measurements were made from an altitude of $\sim 4200 \mathrm{~m}$ (m.s.l.) in the free troposphere. The PBL height was then about $2000 \pm 100 \mathrm{~m}$. As for 19 July, similar values have been observed for optical thicknesses measured on 20 July with $0.25 \pm 0.03$ above Palaiseau AERONET station.

On 31 July, the flight was scheduled between 10:30 and 14:00 UTC. The 31 July event was characterized by westerly advection of clean air masses originating from the Atlantic 
Ocean. However the air mass trapped in the PBL entered the Paris area from the south. From Creil $(36 \mathrm{~km}$ north of Paris), the aircraft headed south at $900 \mathrm{~mm}$.s.l. (Part 1) and performed two legs before climbing (Part 2) to $4200 \mathrm{~m} \mathrm{m.s.1.}$ where lidar measurements were performed on two legs, colocalized respectively with Part 2 and Part 1 . The PBL height was about $1500 \pm 100 \mathrm{~m}$. The mean optical thicknesses were smaller with values of $0.11 \pm 0.03$ above Palaiseau or Creteil (southeast of Paris), $0.15 \pm 0.03$ above Paris and $0.22 \pm 0.04$ above Creil (North of Paris) AERONET stations, but pointing out a significant increase downwind of the urban area.

On 19 and 31 July, we have distinguished two parts, called Part 1 and Part 2 sice these days have long flight legs at $950 \mathrm{~m}$, where the plane was circumventing the urban area. Aerosols measured in the lowest altitudes $(<950 \mathrm{~m})$ are therefore different from aerosols studied over $950 \mathrm{~m}$. Part 1 and Part 2 thus correspond to height ranges where aerosol properties are studied for each specific day. In the following, the lower part (Part 1) moreover corresponds to measurements inside Paris plume, whereas the upper part (Part 2) is related to measurements outside the plume.

\section{Methodology to retrieve vertical profiles of ACRI}

Laboratory experiments can determine the ACRI from bulk aerosol samples (e.g., Volz, 1973). The advantage of estimating ACRI via remote sensing lies in the determination of optical properties of airborne particles under real atmospheric conditions (e.g., Dubovik et al., 2002; Sinyuk et al., 2003; Todd et al., 2007). In a previous study (Raut and Chazette, 2007), we calculated the ACRI through a synergy between lidar, sunphotometer and ground-based instrumentation. ACRI were assessed to be 1.56-0.034i at $355 \mathrm{~nm}$ and $1.59-0.040 \mathrm{i}$ at $532 \mathrm{~nm}$ in Paris, thus leading to single-scattering albedo values between 0.88 and 0.80 , respectively. This determination was nevertheless limited to the surface and only a simulation of vertical profiles of ACRI could be performed to extend the results to the entire PBL. This method was assuming a vertically homogeneous aerosol composition, implying that modifications in vertical profiles were primarily caused by variations of RH in the atmospheric column.

In this study, the evolution of ACRI as a function of altitude can be retrieved from in situ airborne observations and lidar measurements constrained with sunphotometer values. That method will be described in Sect. 3.1. Aircraft in situ measurements often subject the aerosols to changes in $\mathrm{RH}$ between the atmosphere and the instrument (Baumgardner and Huebert, 1993). Corrected ACRI values can therefore be deduced from simulations implying relative humidity profiles simultaneously measured onboard the plane (see Sect. 3.2). Results of the two approaches are compared in Sect. 4. Uncertainties on the real and imaginary parts of the ACRI have been determined using a Monte-Carlo approach thanks to 200 Gaussian random realizations around the variability of size distribution parameters.

\subsection{ACRI retrieval from ascending flight}

The determination of the real part of the ACRI is the result of a convergent method between various scattering crosssections calculated in a Mie model and the scattering crosssection measured by the coupling of nephelometer, particle sizer and particle counter instruments. Using spherical particles in a Mie code is justified by a very low lidar depolarized ratio $(\sim 4 \%)$. The approach has already been described in Raut and Chazette (2007). In this study, the method previously described is applied to the observations of ESQUIF campaign on 19, 20 and 31 July, 2000. Data retrieved from nephelometer at $550 \mathrm{~nm}$ and particle sizer enabled to assess both the ACRI and the single-scattering albedo as a function of altitude. A diagram describing all the numbered steps of our method has been drawn on Fig. 3, including all the comparisons validating the approach and described in Sect. 5. The main steps of the procedure are reminded in the following:

1. Owing to the speed of the plane during ascending phases, measurements from the particle sizer and the nephelometer have been vertically averaged for every $200 \mathrm{~m}$.

2. The second step is the retrieval of the number size distribution. A standard method using the proximity recognition approach was used to retrieve the aerosol size distribution assuming 2 modes in altitude (nucleation and accumulation) with a lognormal distribution. The method consists in best fitting the particle numbers in the classes deduced from the PCASP and the CPC measurements. The distribution is characterized by the modal radius $\left(r_{1}\right.$ and $\left.r_{2}\right)$, the associated geometric dispersions ( $\sigma_{1}$ and $\left.\sigma_{2}\right)$, and the occupation rates $\left(x_{1}\right.$ and $\left.x_{2}=1-x_{1}\right)$. Mean parameters of the lognormal size distributions are given in Table 1.

3. For each altitude level, the Mie code is used to calculate the scattering cross-section for each couple of ACRI chosen in the range 1.3-1.9 for the real part and $10^{-8}$ 0.2 for the imaginary part. $(401 \times 401)$ couples of values of real and imaginary parts belonging to this domain have been considered in this study, enabling the construction of a look-up table of scattering cross-sections for the given altitude.

4. The retrieval of the complex refractive index does not require any iterative procedure. The determination of the real part is however the result of a minimization of the differences between the measured cross-section and a look-up table. The duration of the computations increases with the smoothness of the grid building the look-up table. The whole of the solutions for the 


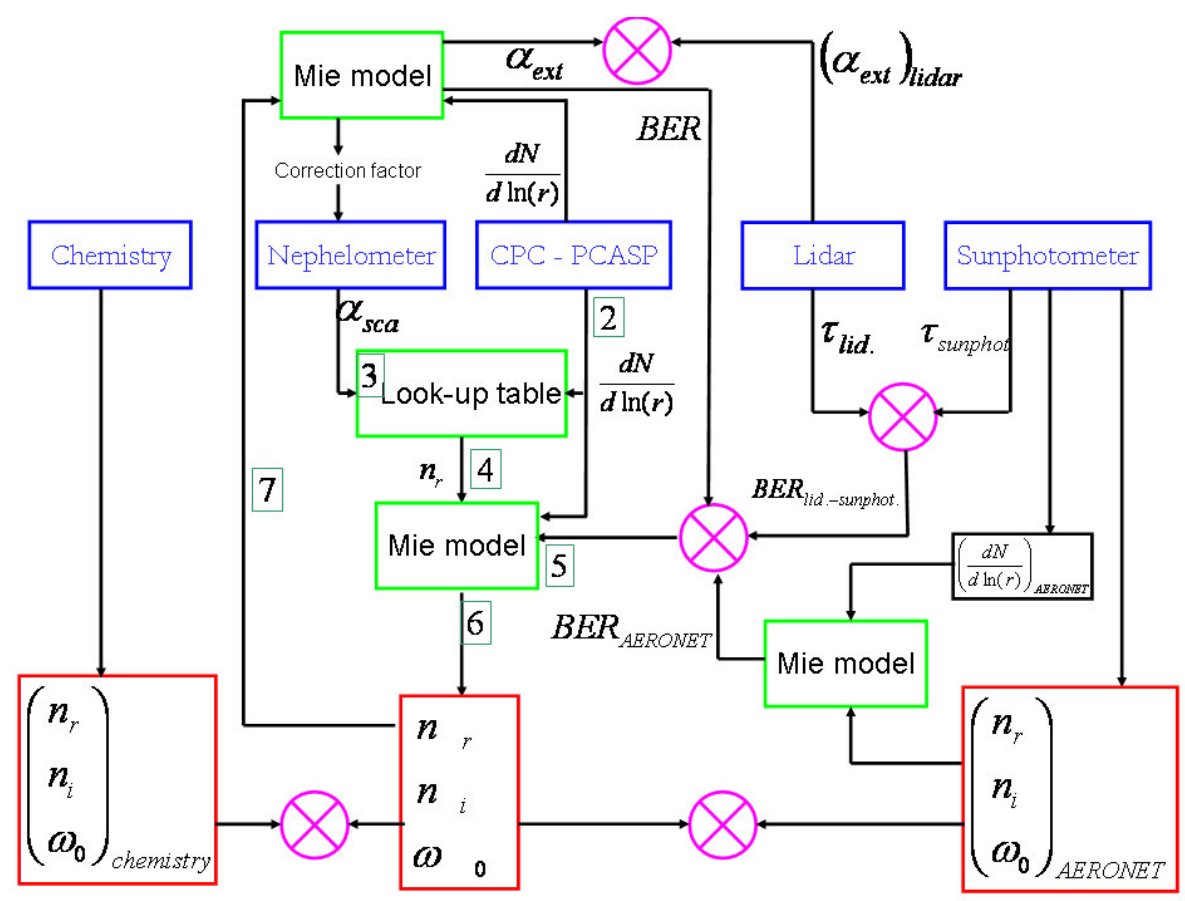

Fig. 3. Diagram of the synergetic approach to retrieved aerosol optical properties: backscatter-to-extinction ratio BER, complex refractive index $\left(n_{r}\right.$ and imaginary $n_{i}$ parts), single-scattering albedo $\omega_{0}$ from optical thicknesses ( $\tau_{\text {sunphot }}$ for sunphotometer and $\tau_{\text {lid }}$ for lidar, integrating extinction coefficient $\alpha_{\text {ext }}$, number size distribution $\frac{d N}{d \ln (r)}$ and scattering-cross section $\alpha_{\text {sca. }}$. Pink circles represent comparisons between optical parameters.

scattering cross-section can be represented by a curve in the plane $\left(n_{r}, n_{i}\right)$, as in Raut and Chazette (2007). The main feature of this curve is the independence of the solution from the real part of ACRI: the real part can be assessed because its observed dispersion is very weak $(<0.02)$ in the likely range of the imaginary part $(<0.05)$ for anthropogenic aerosols from automobile traffic. Hence, the uniqueness of the real part is guaranteed. Automobile traffic is indeed the main source of photooxidant pollution and aerosols in large cities such as Los Angeles (Lurmann et al., 1997) or Paris (Menut et al., 2000). There are naturally other sources of anthropogenic aerosol particles like emissions from plants burning household refuse or airports (quoted in Sect. 4.3), but they can hardly contradict the very large hypothesis $n_{i} \leq 0.05$.

5. Lidar inversion thanks to sunphotometer measurements enabled to retrieve the backscatter-to-extinction ratio (BER) of the entire aerosol vertical column with an iterative procedure, as in Chazette (2003). The BER has been given by Chazette et al. (2005) to be equal to $0.014 \mathrm{sr}^{-1}$ from the synergy between sunphotometer and LEANDRE-1 airborne lidar. An altitude-dependent BER would have been indeed particularly appreciated in this study but the lack of a Raman lidar leads us to sup- pose a constant BER in the atmospheric column. The only way to introduce errorbars on the BER lies on a comparison of the BER from lidar and that calculated using a Mie model and the measured microphysical parameters taking into account $\mathrm{RH}$ profile with altitude. This study will be performed in Sect. 5.5.

6. A set of BER values is then computed thanks to the Mie code for several couples of ACRI whose only the imaginary part can vary, the real part being determined in step 4. The requested imaginary part is thus the one providing the closest BER value than that calculated in step 5. The uniqueness of the real part also triggers off the uniqueness of the imaginary part in this step, where the unknown parameter (imaginary part) is the only one value enabling to simulate a BER equal to the measurement (synergy lidar - sunphotometer). The singlescattering albedo is also determined in this step.

7. The couple of indices retrieved is used together with the size distribution to calculate the scattering phase function, hence the correction factor of the nephelometer, as indicated in Sect. 2.1. A new scattering cross-section is therefore obtained, suggesting a recall to steps 4 to 6 . Renewing this operation is not generally required since the correction factor is stable as of the first iteration. 
Table 2. Mean values of ACRI $\left(n_{r}-i \cdot n_{i}\right)$, single-scattering albedo $\left(\omega_{0}\right)$ and relative humidity (RH) derived from aircraft measurements on 19, 20 and 31 July 2000 during ESQUIF program. The standard deviation is given in parenthesis. The uncertainties due to the retrieval procedure have been computed by a Monte-Carlo method and are also specified.

\begin{tabular}{|c|c|c|c|c|c|c|}
\hline Date & $\begin{array}{l}3 \text { days } \\
\text { Air mass origin }\end{array}$ & Location & $n_{r}$ & $n_{i}$ & $\omega_{0}$ & $\mathrm{RH}(\%)$ \\
\hline \multirow[t]{3}{*}{ 19/07/2000 } & \multirow[t]{3}{*}{ Great-Britain London area } & $\begin{array}{l}\text { Part } 1 \\
\text { Upwind } \\
\text { Inside the plume }\end{array}$ & $\begin{array}{l}1.479 \\
( \pm 0.014)\end{array}$ & $\begin{array}{l}0.020 \\
( \pm 0.003)\end{array}$ & $\begin{array}{l}0.871 \\
( \pm 0.016)\end{array}$ & $\begin{array}{l}51.6 \\
( \pm 4.3)\end{array}$ \\
\hline & & $\begin{array}{l}\text { Part } 2 \\
\text { Downwind } \\
\text { Outside the plume }\end{array}$ & $\begin{array}{l}1.501 \\
( \pm 0.005)\end{array}$ & $\begin{array}{l}0.013 \\
( \pm 0.002)\end{array}$ & $\begin{array}{l}0.919 \\
( \pm 0.009)\end{array}$ & $\begin{array}{l}57.8 \\
( \pm 4.5)\end{array}$ \\
\hline & & $\begin{array}{l}950 \mathrm{~m} \\
\text { Downwind } \\
\text { Inside Paris plume }\end{array}$ & $\begin{array}{l}1.450 \\
( \pm 0.007)\end{array}$ & $\begin{array}{l}0.014 \\
( \pm 0.002)\end{array}$ & $\begin{array}{l}0.896 \\
( \pm 0.014)\end{array}$ & $\begin{array}{l}48.5 \\
( \pm 2.1)\end{array}$ \\
\hline 20/07/2000 & Great Britain Cardiff area & $\begin{array}{l}\text { Upwind } \\
\text { Inside the plume } \\
320 \mathrm{~m} \\
\text { Downwind } \\
\text { Inside Paris plume }\end{array}$ & $\begin{array}{l}1.518 \\
( \pm 0.015) \\
1.461 \\
( \pm 0.007)\end{array}$ & $\begin{array}{l}0.020 \\
( \pm 0.004) \\
0.017 \\
( \pm 0.002)\end{array}$ & $\begin{array}{l}0.883 \\
( \pm 0.019) \\
0.883 \\
( \pm 0.013)\end{array}$ & $\begin{array}{l}51.8 \\
( \pm 11.8) \\
48.1 \\
( \pm 2.5)\end{array}$ \\
\hline \multirow[t]{2}{*}{$31 / 07 / 2000$} & \multirow[t]{2}{*}{ Atlantic Ocean } & $\begin{array}{l}\text { Part } 1 \\
\text { Downwind } \\
\text { Inside the plume }\end{array}$ & $\begin{array}{l}1.483 \\
( \pm 0.015)\end{array}$ & $\begin{array}{l}0.014 \\
( \pm 0.002)\end{array}$ & $\begin{array}{l}0.913 \\
( \pm 0.015)\end{array}$ & $\begin{array}{l}61.1 \\
( \pm 3.7)\end{array}$ \\
\hline & & $\begin{array}{l}\text { Part } 2 \\
\text { Upwind } \\
\text { Outside the plume }\end{array}$ & $\begin{array}{l}1.547 \\
( \pm 0.009)\end{array}$ & $\begin{array}{l}0.013 \\
( \pm 0.002)\end{array}$ & $\begin{array}{l}0.927 \\
( \pm 0.012)\end{array}$ & $\begin{array}{l}66.6 \\
( \pm 5.8)\end{array}$ \\
\hline \multicolumn{3}{|c|}{ Uncertainties from Monte-Carlo method } & 0.020 & 0.003 & 0.015 & 0.5 \\
\hline
\end{tabular}

Theoretically, an aerosol size distribution might present different indices of refraction corresponding to each mode in the distribution, whereas the measured scattering coefficient and the BER are global features of the aerosols at a given altitude. The convergence of a Mie code towards those two measured parameters can be seen as the resolution of a system with two equations and two unknown parameters (one real part and one imaginary part). Taking into account the different indices in each mode would assume the introduction of supplementary unknown values without additional constraint. In this case, the methodology would not permit to deduce a unique couple of solutions.

The merit of this technique is that it provides, for the first time, vertically resolved ACRI with such a high vertical resolution.

\subsection{Influence of RH profile}

To model the effect of water vapor on hydrophilic aerosols, we used the following relationships set up by Hänel (1976), describing aerosol growth and giving particle radius and refractive index for wet particles:

$r_{w}=r \cdot\left(\frac{1-\mathrm{RH}}{1-\mathrm{RH}_{\mathrm{ref}}}\right)^{-\varepsilon}$
$n_{w}=n_{\mathrm{H}_{2} \mathrm{O}}+\left(n-n_{\mathrm{H}_{2} \mathrm{O}}\right) \cdot\left(\frac{r_{w}}{r}\right)^{-3}$

The suffix $w$ refers to wet conditions and $\mathrm{RH}$ is the relative humidity. $r$ and $n$ are the radius and the refractive index of aerosol particles, respectively, at $\mathrm{RH}=\mathrm{RH}_{\text {ref }}$, and $n_{\mathrm{H}_{2} \mathrm{O}}$ is the refractive index of pure water. The coefficient $\varepsilon$ depends on the considered type of aerosol and is taken as 0.26 according to the chemical composition of Paris urban aerosol analyzed by Randriamiarisoa et al. (2006). That study had shown that the water soluble fraction was belonging to the accumulation mode indicating that the retrieved $\varepsilon$ represents hygroscopicity of the accumulation mode. The coarse mode particles did not appear hydrophilic. Hänel's laws essentially apply for $\mathrm{RH}$ larger than $\mathrm{RH}_{\mathrm{ref}}=55 \%$ because of the existence of deliquescence point (Randriamiarisoa et al., 2006). Simulations of ACRI profiles, starting from the measurements at each altitude with a RH lower than $55 \%$, have been realized in both Part 1 and Part 2. The calculations have been performed independently for each altitude.

\section{Results}

Vertical profiles of ACRI (real and imaginary parts) are given in Fig. 4 for 19, 20 and 31 July, 2000 over Paris area. Red solid lines represent the mean profile obtained during the 
(a)

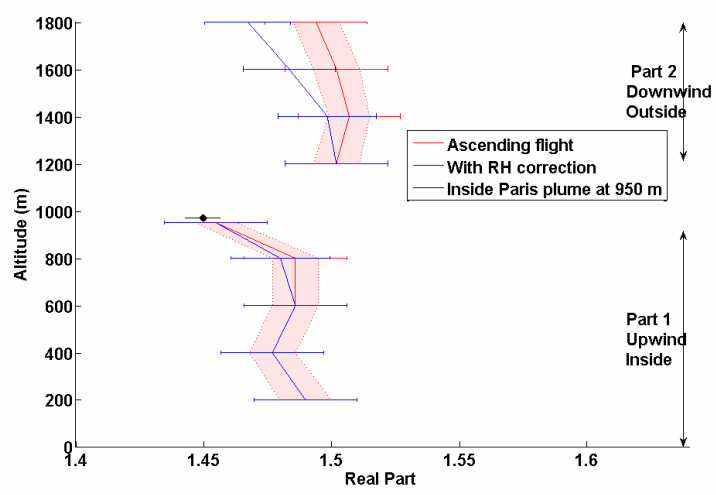

(c)

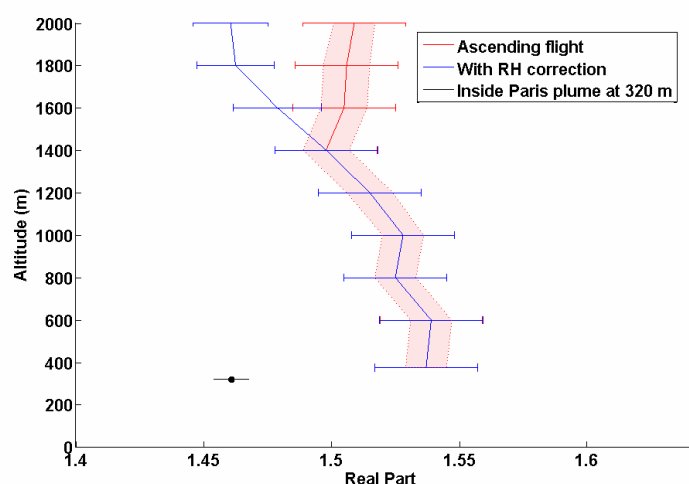

(e)

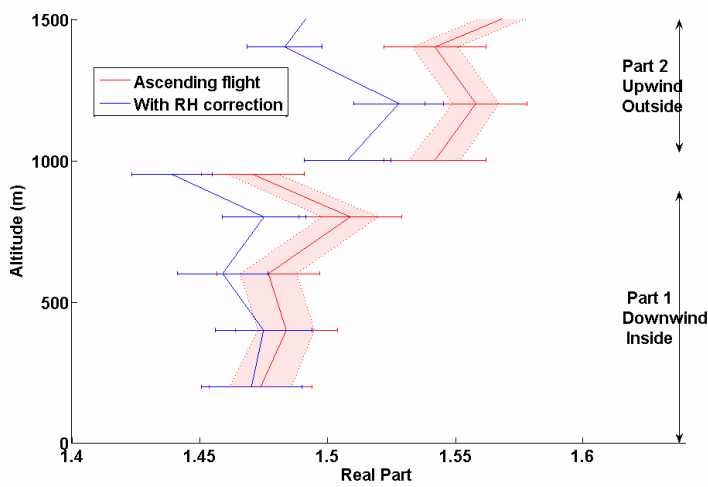

(b)

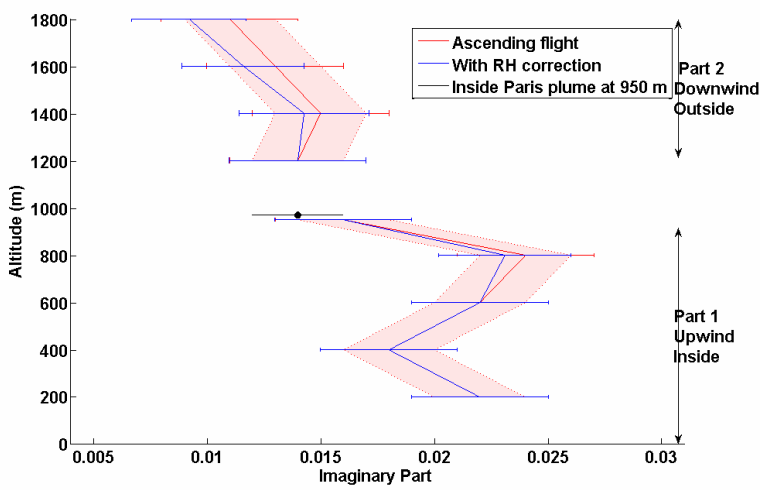

(d)

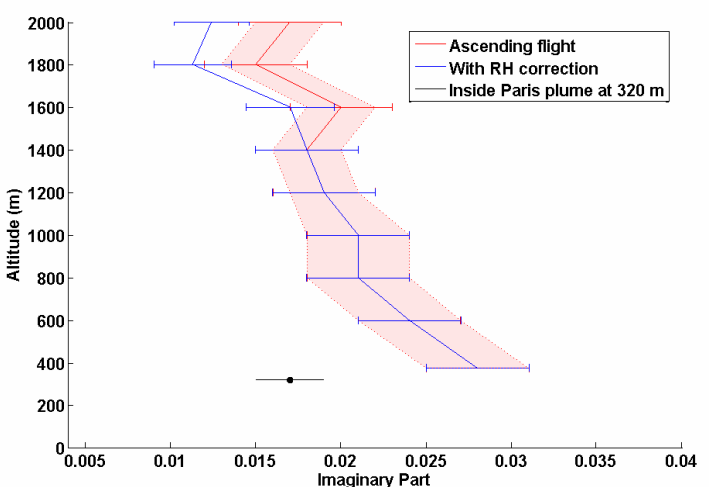

(f)

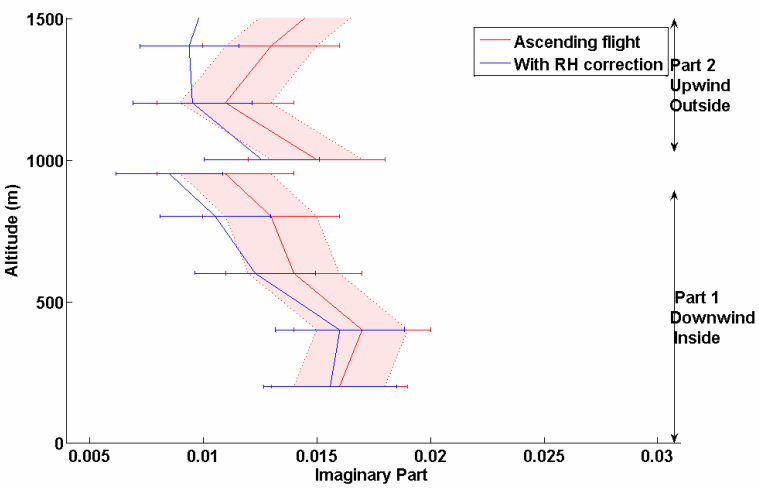

Fig. 4. Vertical profiles of the complex refractive index (real (a, c and e) and imaginary (b, d and f) parts), on 19 (a, b), 20 (c, d) and 31 (e, f) July, 2000 over Paris area. Red solid lines represent the mean profile obtained during the ascending parts of the flight, shaded areas show their respective standard deviation and horizontal lines give the uncertainties determined by a Monte-Carlo method. Blue solid lines represent the mean profile obtained by a simulation combining in situ retrievals and relative humidity profiles, and horizontal lines show the uncertainties determined by a Monte-Carlo method.

ascending parts of the flight, shaded areas show their respective standard deviation and horizontal lines give the uncertainties determined by a Monte-Carlo method. Blue solid lines represent the mean profile obtained by a simulation combining dry in situ retrievals and relative humidity profiles, and horizontal lines show their respective uncertainty
$\Delta n_{w}$ computed by the following equation:

$$
\begin{aligned}
\Delta n_{w} & =\left(n_{w}-n_{\mathrm{H}_{2} \mathrm{O}}\right) \cdot\left[\left(\frac{\Delta n}{n-n_{\mathrm{H}_{2} \mathrm{O}}}\right)^{2}+\left(\frac{3 \cdot \varepsilon \cdot \Delta \mathrm{RH}}{1-\mathrm{RH}}\right)^{2}\right. \\
& \left.+\left(\frac{3 \cdot \varepsilon \cdot \Delta \mathrm{RH}}{1-\mathrm{RH}_{\mathrm{ref}}}\right)^{2}\right]^{0.5}
\end{aligned}
$$


where $\Delta n=0.02-\mathrm{i} 0.003$ is the uncertainty retrieved for the dry ACRI (Table 2) and $\Delta \mathrm{RH} \approx 0.5 \%$ is the uncertainty on the measurements of relative humidity. Average values of ACRI, single-scattering albedo and RH over the entire PBL, Part 1 or Part 2, with their corresponding standard deviations have been reported in Table 2 .

\section{$4.1 \quad 19$ July}

The similarity in the profiles of both real and imaginary parts retrieved by the two methods (Fig. $4 \mathrm{a}$ and $\mathrm{b}$ ) indicates that their modifications in the column are not mainly due to $\mathrm{RH}$ profile. Taking into account the uncertainties, the two profiles overlap up to the top of the PBL $(1800 \mathrm{~m})$, indicating that RH correction has only a slight influence for 19 July. RH seldom exceeds $60 \%$, i.e. a bit over the deliquescence threshold, which accounts for the very small shift between the profiles over $1300 \mathrm{~m}$. Aerosols are not very hygroscopic (Randriamiarisoa, 2006). Nevertheless, the two parts in the profile (below and above $950 \mathrm{~m}$ ) must be set apart because both the real and the imaginary parts remain almost constant in each part of the profiles independently. The changes in aerosol properties between these two domains are indeed correlated to different source regions. Aerosols located upwind of Paris show smaller real part (1.48) but higher imaginary part (0.02) than particles located downwind of Paris but outside the Parisian plume (1.50-i0.013). An additional value of ACRI has been computed inside Paris plume close to $48.45^{\circ} \mathrm{N}$ and $2.13^{\circ} \mathrm{E}$ during the flight at $950 \mathrm{~m} \mathrm{~m} . s .1$. and plotted on Fig. 4. We found 1.45( \pm 0.01$)-\mathrm{i} 0.015( \pm 0.002)$, thus presenting smaller values for real and imaginary parts than aerosols in Part 1 coming from England (Fig. 2a). The total number of particles is higher downwind of Paris but this noticeable increase $(55 \%)$ is associated with a scattering coefficient that hardly evolves $\left(\sim 0.15 \mathrm{~km}^{-1}\right)$ between the north and the south of Paris. That can be explained by the production of aerosols in the nucleation mode $(\sim 0.04 \mu \mathrm{m})$ over Paris area, which have only a few influence on the aerosol optical properties at $532 \mathrm{~nm}$. An increasing amount of particles yields to a smaller mean value of the real part of ACRI. The fact that scattering properties do not vary suggests that the incoming air mass was characterized by a size distribution already dominated by the accumulation mode $(\sim 0.12 \mu \mathrm{m})$ as it could be expected for an atmospheric flow polluted by aerosols having aged for several days. That is in accordance with Randriamiarisoa et al. (2006) who showed that aerosols were mainly hydrophobic on 19 July: polluted air masses arriving over Paris are loaded with aged particles coming from Great Britain. The influence of the city of Paris producing aerosols in the nucleation mode is not therefore paramount for the scattering coefficient.

\subsection{July}

On the 20 July, given that the deliquescence point has not been reached below $1500 \mathrm{~mm}$.s.l., the influence of RH on ACRI profile cannot be remarked (Fig. 4c). Differences on the real part are observed near the top of the PBL since RH correction effect becomes important for $\mathrm{RH}$ values larger than $70 \%$. This effect is not significant on the imaginary part owing to the uncertainties. The main tendency observed on Fig. $4 \mathrm{~d}$ is the regular decrease of the imaginary part as a function of the altitude. On 20 July, the evolution of the ACRI versus altitude has been retrieved upwind of Paris (north of Paris), given that no ascending flight has been performed in the south of Paris. According to the backward trajectory plotted on Fig. 2b, the optical properties of the aerosols coming from Great Britain are mainly located in the upper part of the profiles. These highest altitudes are also associated with higher scattering coefficients $\left(0.16 \mathrm{~km}^{-1}\right)$ than the area close to the surface $\left(0.12 \mathrm{~km}^{-1}\right)$. The corresponding values of ACRI $(1.50( \pm 0.01)-\mathrm{i} 0.017( \pm 0.002))$ is in agreement with that derived for 19 July. The explanation of ACRI evolution with altitude for 19 July can also be provided for 20 July since air masses present quite similar origins: hydrophobic aerosols are advected in aged air masses from England. The observed differences between the lowest and the highest altitudes are however very weak and may be ascribed to the natural variability of the ACRI for the corresponding aged aerosol. As for 19 July, we calculated one value of ACRI downwind of the plume. The calculation performed at $320 \mathrm{~m}$ m.s.l. close to $48.12^{\circ} \mathrm{N}$ and $2.52^{\circ} \mathrm{E}$ has given a mean value of $1.46( \pm 0.01)-\mathrm{i} 0.017( \pm 0.002)$, also plotted on Fig. 4, corroborating the result of the previous day for the air mass downwind of Paris inside the plume.

\section{$4.3 \quad 31$ July}

As for the 19 July, profiles are divided in two parts on the 31 July (Sect. 2.2): Part 1 (lower part) and Part 2 (upper part). One should however notice that the results obtained at $800 \mathrm{~m}$ can be considered outside the plume (Part 2) since the plane was circumventing the urban area at this altitude to prepare a leg at $950 \mathrm{~m}$ (see Fig. 1e). The situation observed on 31 July is quite different. RH values are much higher than for 19 and 20 July. RH were found close to $55 \%$ at the surface but can reach 70\% in Part 1 (Fig. 1f), 75\% in Part 2 and increase up to $80 \%$ at the top of the PBL. The discrepancies between the profiles of ACRI retrieved from dry measurements and the simulated profiles through RH measurements is obvious on both Part 1 and Part 2, and particularly in the vicinity of the top of the PBL (1500 m) when ACRI profile determined through RH profile quickly decreases. Moreover, a sharp contrast between the two parts can be remarked in Fig. $4 \mathrm{e}$ and the variability of the ACRI versus altitude is relevant since uncertainty bars do not overlap. Aerosols measured outside Paris plume have a larger scattering efficiency 
(higher real part of ACRI) than particles inside the plume (1.55 in Part 2 compared to 1.48 in Part 1): outside the plume, aerosols are indeed farther from the sources and may also stem from a more rural origin. The air mass has circumvented Paris region by South side before coming onto the measurement site, thus flying over rural areas. When arriving over the Paris area, the incoming clean air mass is contaminated by pollution; fast aerosol aging processes are therefore being observed more distinctly than in the 19 and 20 July cases. In Part 1, aerosols located in the plume of Paris show small values of ACRI, as already observed for 19 and 20 July. Notwithstanding, these particles are accompanied by a significant amount of aerosols produced by intense aircraft traffic influenced by Charles de Gaulle Airport. Those particles barely contribute to the overall aerosol optical properties in the visible spectral range. The retrieval of lidar profiles (see Sect. 5.4) for the 31 July points out the differences in aerosol extinction coefficient between the two parts: values have been established to be $\sim 0.07 \mathrm{~km}^{-1}$ in Part 1 within the Paris plume, compared to $0.11 \mathrm{~km}^{-1}$ outside the plume. Given that the shape of the size distribution within the plume (Table 1) associated with a high number of particles cannot explain such low extinction value relative to that determined outside the plume, we should consider that low values for the real part (1.46-1.48) can ascertain a low extinction coefficient. In order to validate this result, we computed the ACRI over two legs at $950 \mathrm{~m}$ respectively located at $48.75^{\circ} \mathrm{N}$ (upwind of Paris) and $48.96^{\circ} \mathrm{N}$ (downwind of Paris). Results are plotted on Fig. 5. As expected, the real part is lower (1.42-1.47) in the Paris plume, and show larger values (1.48-1.54) when the aircraft is farther from Paris, i.e. for longitude lower than 1.7 or larger than 2.7. In addition, this figure shows that the averaged value downwind of Paris is a bit weak $(1.44 \pm 0.02)$ in comparison with the mean value retrieved before Paris (1.45 \pm 0.02$)$.

\section{Discussion}

\subsection{Comparison to previous studies}

Values determined in this study are coherent with those retrieved by other authors. Average values over the entire PBL with their corresponding standard deviations have been reported in Table 2. A good agreement is found between the mean value of ACRI, that is $1.51( \pm 0.02)-\mathrm{i} 0.017( \pm 0.003)$, and several studies. It is for instance in accordance with the results of Shettle and Fenn (1979) who found 1.56-0.08i for small urban aerosols at RH close to $50 \%$ using different models and Ebert (2004) with an ACRI close to $1.6( \pm 0.1)-\mathrm{i} 0.04$ $( \pm 0.02)$ at $532 \mathrm{~nm}$ for urban aerosols where high real parts were predominantly caused by the high abundance of metal oxide/hydroxide particles, the high imaginary parts by high abundances of soot.

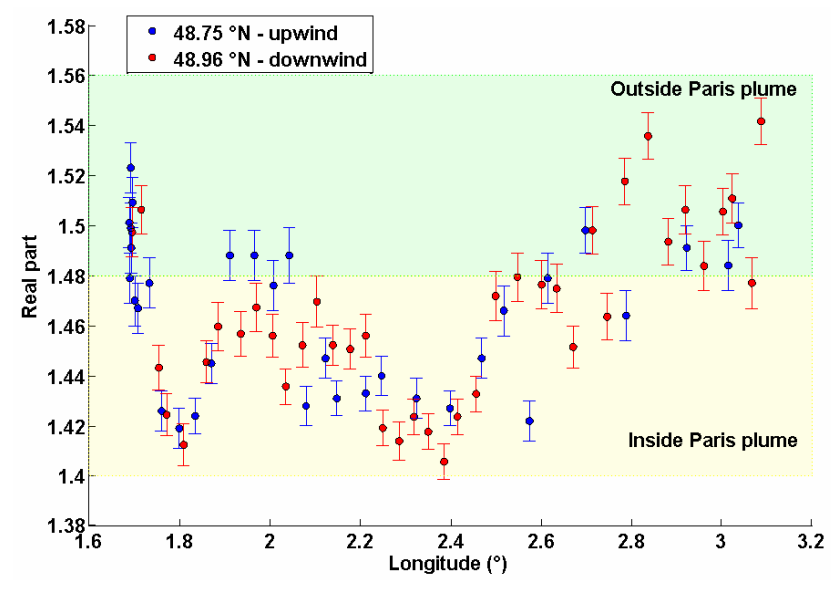

Fig. 5. Evolution of the real part of the ACRI during the leg performed at $950 \mathrm{~m}$ as a function of longitude for $31 \mathrm{July}, 2000$. Blue dots correspond to measurements at the latitude of $48.75^{\circ} \mathrm{N}$ (upwind of Paris) and red dots to measurements at $48.96^{\circ} \mathrm{N}$ (downwind of Paris). Vertical bars show the uncertainties.

Thanks to a Raman lidar, Ferrare et al. (1998) found that the real part was varying between 1.4 and 1.5 for dry aerosol $( \pm 0.05)$ and between 1.37 and 1.4 for wet aerosol, associated with a single-scattering albedo above $0.94 \pm 0.1$. Multiwavelength backscatter and extinction lidar measurements enabled Müller et al. (2002) to deduce a mean wavelengthindependent ACRI of 1.56-0.009i. But the real part of the ACRI had an uncertainty up to 0.1 , the imaginary part could be estimated only with an accuracy of one order of magnitude, and in some cases for rather small particle effective radii, real and imaginary parts may be slightly overestimated. Redemann et al. (2000) combined lidar, sun photometer and particle sizers data to retrieve both real and imaginary parts in the atmospheric column over Atlantic Ocean that would provide the same backscatter signal in a forward calculation. Values of the estimated ACRI range from 1.33 to 1.45 for the real part and 0.001 to 0.008 for the imaginary part.

Table 3 summaries the results of those different approaches.

\subsection{Comparison to AERONET measurements}

The only available estimates of the aerosol refractive index for the time and location of this experiment are those given on the website of the AERONET network (Holben et al., 1998). The principle of such a comparison has been included in Fig. 3. The average complex refractive index, over the entire month of July 2000 , was calculated to be $1.5( \pm 0.05)$ $\mathrm{i} 0.016( \pm 0.0125)$ at $670 \mathrm{~nm}$, after rejection of aberrant data with refractive indices close to that of water. The standard deviations, associated to the mean values, reflect both the temporal variability of the aerosol properties and the error on the retrieved parameters. The mean value of ACRI retrieved 
Table 3. Values of ACRI retrieved from different studies.

\begin{tabular}{lll}
\hline Author & Measurements & Values of ACRI \\
\hline Shettle and Fenn (1979) & Small urban aerosols at RH close to 50\% & $1.56-\mathrm{i} 0.08$ \\
Ebert (2004) & Urban aerosols & $1.6( \pm 0.1)-\mathrm{i} 0.04( \pm 0.1)$ \\
Ferrare et al. (1998) & Tropospheric aerosols in Oklahoma: & $1.4-1.5( \pm 0.05)$ \\
& $\begin{array}{l}\text { Dry aerosols } \\
\text { Tropospheric aerosols in Oklahoma: }\end{array}$ & $1.37-1.4$ \\
& Wet aerosols & \\
Müller t al. (2002) & Pollution plumes advected from the European & $1.56( \pm 0.1)-\mathrm{i} 0.009( \pm$ one order of magnitude) \\
Redemann (2002) & Over Atlantic Ocean & \\
This study & Mean value over 19, 20 and 31 July 2000 in & $1.33-1.45-\mathrm{i} 0.001-0.008$ \\
& Paris area & \\
\hline
\end{tabular}

in this study is thus very close to that provided by AERONET data.

In a more general context, it is important to assess the representativeness of our measurements. We used almucantar data obtained over Paris area for clear-sky conditions during summertime between 1999 and 2007. This method of retrieving the ACRI and single-scattering albedo uses the sun and sky radiance measurements acquired by the sun photometer when the instrument scans in the solar almucantar. In order to compare these results with the measurements presented in this study, we computed ACRI values and singlescattering albedos at $532 \mathrm{~nm}$, assuming a linear approximation for ACRI between 438 and $669 \mathrm{~nm}$ and using the following equations for the single-scattering albedo at $532 \mathrm{~nm}$ $\omega_{0532}$ :

$\tau_{532}=\tau_{438} \cdot\left(\frac{532}{438}\right)^{-a}$ where $a=\frac{\ln \left(\frac{\tau_{669}}{\tau_{438}}\right)}{\ln \left(\frac{438}{669}\right)}$

$\omega_{0532}=\frac{\tau_{532}^{\text {extinction }}-\tau_{532}^{\text {absorption }}}{\tau_{532}^{\text {extinction }}}$

where $\tau_{i}$ is the aerosol optical thickness at $i \mathrm{~nm}$ for extinction or absorption respectively, $a$ the Angström exponent (Angström, 1964).

The occurrences of the $532 \mathrm{~nm}$ single-scattering albedo, real part and imaginary part of the ACRI are given in Fig. 6 for clear-sky conditions during summertime between 1999 and 2007 in the Paris area. The mean values of singlescattering albedo retrieved in this study for 19, 20 and 31 July 2000 are located in the center of the Gaussian curve, indicating that such single-scattering albedo values between 0.89 and 0.92 are representative of the region in summer. Real parts also form a Gaussian curve but their values are slightly lower than our results. We should however notice that the mean real part from almucantar retrievals is 1.45 with an uncertainty of 0.04 (Dubovik et al., 2000), thus in agreement with the small real parts derived in Paris plume in Sect. 4: 1.46-1.48. The shape of the histogram for the imaginary parts is noisier but the mean values found for 19, 20 and 31 July are in the range of almucantar retrievals. Dubovik et al. (2000) indeed pointed out the high uncertainties on imaginary parts: 30\% for strongly absorbing aerosols and 50\% for weakly absorbing aerosols.

\subsection{Comparison with chemical analyses}

Chemical analyses on filters were performed for 19 and 20 July 2000 and results of the mass apportionment are given in Fig. 7, together with the corresponding values of ACRI derived from Chazette and Liousse (2001). Independently of the Mie calculations, we chemically derive the ACRI by using the known ACRI of individual constituents of aerosols (Fig. 3). A simple mass-linear internal mixing rule of the aerosol chemical constituents has been examined for this study, as many authors (e.g. Horvath, 1998). This approach assumes that the particles are homogeneously internally mixed, and that each component contributes to scattering and absorption according to its mass fraction, as:

$n=\frac{\sum_{i} m_{i} \cdot n_{i}}{\sum_{i} m_{i}}$

where $n$ is the calculated ACRI for the particle, $m_{i}$ and $n_{i}$ the mass concentration and refractive index, respectively, of each of the chemical compounds.

We found a mean value of $1.52-\mathrm{i} 0.02$ for both 19 and 20 July, which is in good agreement with the optically-derived ACRI in this paper. We should however be careful on the comparison and discussion of the imaginary parts that are not as well known as their real counterparts, even if values are in accordance. In this study, we deduced values of ACRI by the combination of remote sensing and in situ techniques that are therefore representative of mixture with a composite ACRI, called "effective index". We showed however that aerosols 
(a)

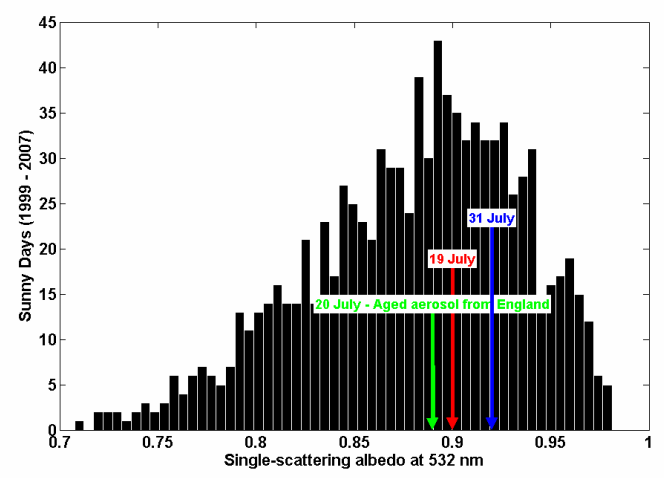

(c)

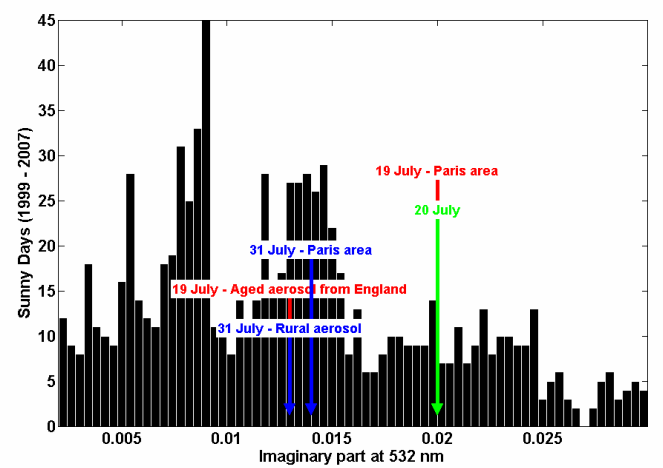

(b)

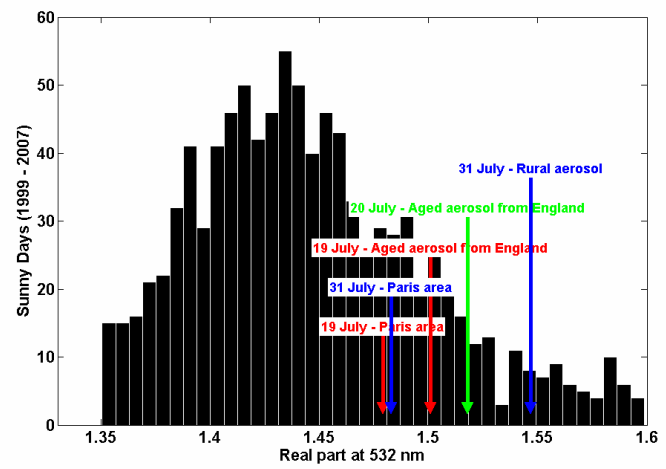

Fig. 6. Histogram of the $532 \mathrm{~nm}$ single-scattering albedo (a), real part (b) and imaginary part (c) of the ACRI for clear-sky conditions during summertime between 1999 and 2007 in the Paris area and retrieved from AERONET Almucantar measurements. The mean values of the present study for 19, 20 and 31 July 2000 are indicated.

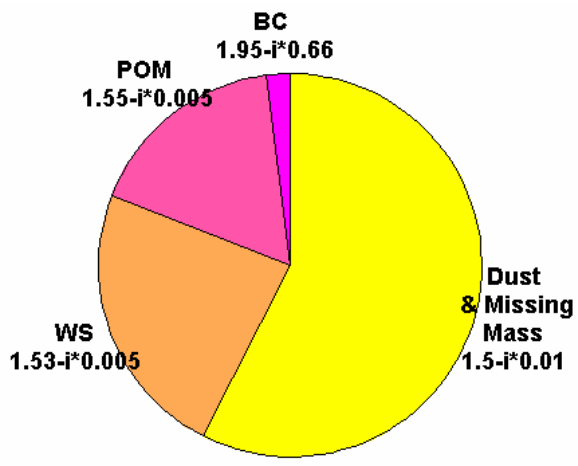

19 July 2000

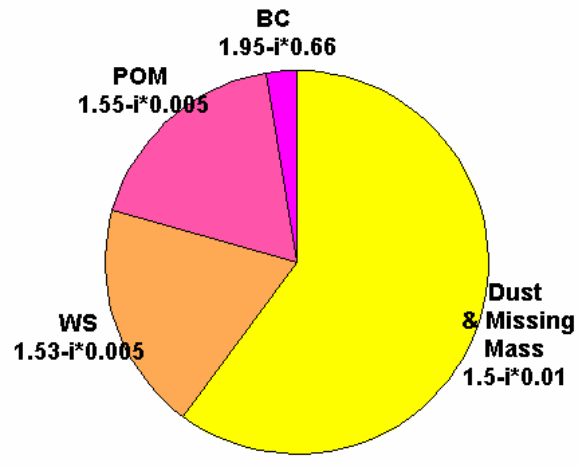

20 July 2000

Fig. 7. Mass apportionment and the corresponding values of ACRI derived from chemical analyses on filters for 19 and 20 July 2000 . ACRI for black carbon (BC) are from Ackerman and Toon (1981), Faxvog and Roessler (1978), particulate organic matter (POM) from Sloane (1984), Holben et al. (1991), Anderson et al. (1996), Von Hoyningen et al. (1998), water soluble fraction (WS) from Sloane (1984), Volz (1973), Dust from d'Almeida et al. (1991).

measured over Paris on 19 and 20 July were carried by aged air masses arriving from industrialized areas in England. Particles have had the time to gather chemical components leading to aerosols constituted of carbonaceous core coated with non-absorbent material. Assessing the absorbing effects of such aerosols is delicate due to multiple-scattering inside the particles before the light reaches the absorbent core. The advantage of our optical retrievals is that they do not take into account the manner in which absorbing particles are represented in the aerosol mixture. 
Table 4. ACRI values for different states of mixture from chemical analyses on 19 and 20 July 2000 over Paris.

\begin{tabular}{llll}
\hline Day & $\begin{array}{l}\text { Homogeneously } \\
\text { internally mixed }\end{array}$ & $\begin{array}{l}\text { Fine and coarse modes } \\
\text { externally mixed } \\
\text { Fine aerosols homoge- } \\
\text { neously internally mixed }\end{array}$ & $\begin{array}{l}\text { Fine and coarse modes } \\
\text { externally mixed } \\
\text { Fine aerosols } \\
\text { externally mixed }\end{array}$ \\
\hline 19 July & $1.525-\mathrm{i} 0.020$ & $1.558-\mathrm{i} 0.036$ & $1.536-\mathrm{i} 0.015$ \\
20 July & $1.527-\mathrm{i} 0.023$ & $1.565-\mathrm{i} 0.049$ & $1.543-\mathrm{i} 0.021$ \\
\hline
\end{tabular}

We performed a sensitivity study on the mixture state of the aerosols so as to assess the errors introduced when assuming that particles are internally mixed. The homogeneous internal mixture supposes that any portion of the particle would have the same composition as the particle itself. The first error in assuming that all particles are internally mixed is the mixing of both accumulation (fine) and coarse modes, whereas dust particles are generally independent. We have therefore considered the case of an external mixture of dusts and well-mixed fine particles and investigate through a Mie code the equivalent ACRI for the whole size distribution that gives the same scattering coefficient and singlescattering albedo as the external mixture. In comparison with the global homogeneous internal mixing, both real and imaginary parts of the refractive index dramatically increase by $20 \%$ and $100 \%$ respectively. The determination of the equivalent index is indeed driven by the accumulation mode, which is the most optically efficient, as shown by Randriamiarisoa et al. (2006). In this mode, refractive indices are mass averaged and the entire particles containing soot are assumed absorb since all waves passing through the particle have potential to be absorbed. That explains the overestimation in the role of soot and thus in refractive index values.

The second error concerns the mixing of black carbon within the fine part of size distribution. Although black carbon may be internally-mixed with other components in a particle, black carbon cannot be well-mixed since soot is irregularly shaped and solid, containing from 30-2000 graphitic spherules aggregated by collision during combustion (Katrinak et al., 1993). Thus black carbon must be distinct and not a well-mixed component of the particle. We have therefore divided each particle belonging to the fine mode into two smaller particles: one is only constituted of black carbon and the second one is an homogeneous mixture of particulate organic matter and water soluble fraction. It is then possible to assess an ACRI for the fine part providing the same scattering coefficient and single-scattering albedo as calculated through a Mie code. Hence we used as input parameter a size distribution with two modes (one for soot, one for organic matter and water soluble) whose modal radius were given by the mass fractions in the fine part. The same method applied to the external mixture of fine and coarse aerosols finally provides the equivalent ACRI for the entire aerosol size distribution. As expected, the influence of the black carbon amount on ACRI values is lower since soot represents very small particles that do not have a strong effect on optical efficiency. Table 4 summaries the different values of ACRI computed with chemical analyses considering the different states of mixture.

Jacobson (1999) reported that transmission electron microscopy indicates that the coating of elementary carbon is also a plausible physical configuration and his calculations showed that the absorption cross-sections of the core treatment were greater than those of elementary carbon particles externally mixed from water particles and less than those of well mixed elementary carbon - water particles. The actual ACRI values in our study are thus probably between the extrema given in Table 4.

\subsection{Comparison with lidar profiles}

Vertical extinction profiles can be retrieved from ACRI and size distributions determined in the atmospheric column. Aerosol extinction coefficient is indeed the product of the particle number concentrations by their scattering crosssection. Extinction coefficient profiles have been computed through a Mie model thanks to in situ measurements during flights and compared to lidar profiles, as shown on Fig. 3. A Monte-Carlo method has been developed to assess the uncertainties of ACRI, size distribution and RH on the aerosol scattering cross-sections. So as to clearly distinguish calculations inside from calculations outside the plume and to easily compare the profiles, lidar profiles from nadir pointing measurements performed at an altitude of $\sim 4200 \mathrm{~m} \mathrm{~m}$.s.l. in the free troposphere are selected in latitude and longitude to be the nearest to in situ measurements (see Sect. 2.2). Results are given in Fig. 8. The general tendency of the profiles is well represented and within the dispersion of lidar values, particularly for 20 and 31 July, but the precise shape cannot be accurately reproduced. In particular the structure with two peaks appearing on 19 July right before the top of the PBL, which may be ascribed to a residual aerosol layer, misses on the calculated profile. That can be linked to a loss of information during the average of ACRI values every $200 \mathrm{~m}$ m.s.1..

The influence of $\mathrm{RH}$ on the extinction coefficient can also be discussed: on 19 July, the lidar signal is not sensitive to 
(a)

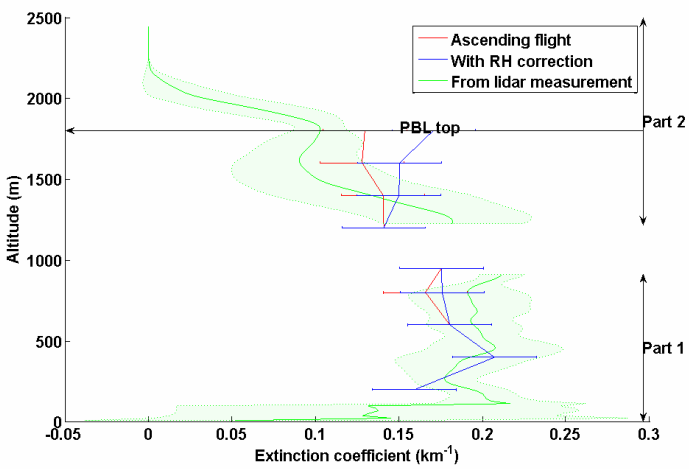

(c)

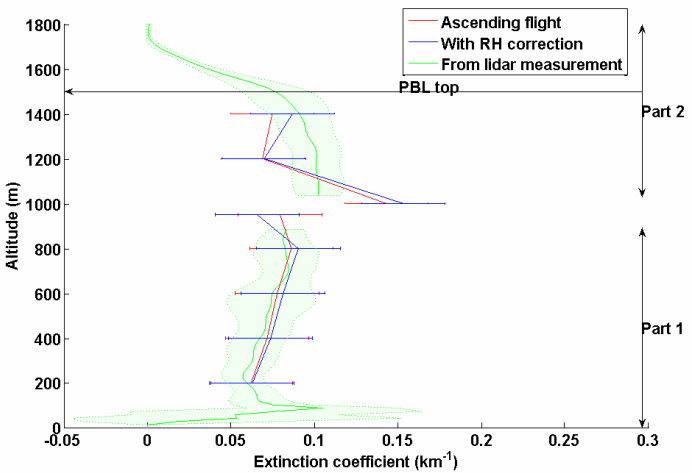

(b)

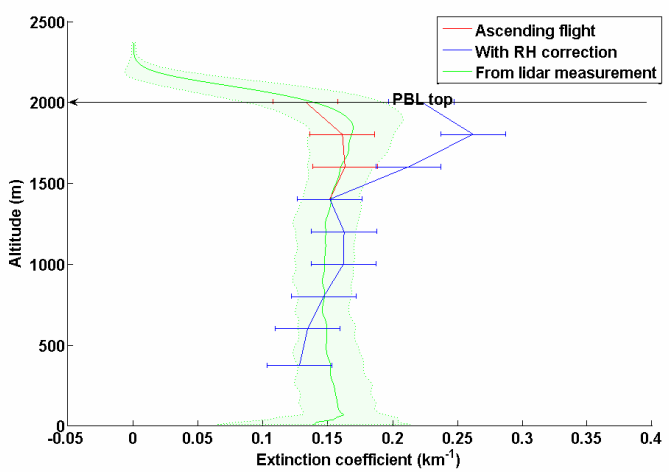

Fig. 8. Vertical profiles of extinction coefficient on 19 (a), 20 (b) and 31 (c) July, 2000 over Paris area. Red solid lines represent the mean profile obtained during the ascending part of the flight and horizontal lines give the uncertainties determined by a Monte-Carlo method. Blue solid lines represent the mean profile obtained by a simulation combining in situ retrievals and relative humidity profiles together with their uncertainties. Green solid line represents the mean lidar profile obtained on the leg located over the ascending parts of the flight; shaded areas show the standard deviation on lidar measurements.

RH in the PBL because the simulated profile of extinction coefficient is closer to lidar measurements without Hänel's corrections. Not surprisingly, $\mathrm{RH}$ profiles were found to increase from $45 \%$ at the surface to only $60 \%$ at the top of the PBL. Furthermore the fact that the profile without RH correction is the closest one in comparison with lidar-derived extinction profile could be an indication that for 19 July the aerosols in the accumulation mode were essentially hydrophobic. That result is in accordance with Randriamiarisoa et al. (2006).

On 20 July, Fig. 8b shows that the RH correction increases the aerosol extinction, while conversely decreasing the BER from 14 to 13.2 (Sect. 5.5). This indicates that aerosol backscattering increases more rapidly with RH correction than extinction. In comparison with 19 July, the effect of RH correction on the shape of aerosol extinction profile is more pronounced, meaning that varying the ACRI and size distribution of the dry particles has a great impact on the magnitude of aerosol extinction. However, the change in aerosol extinction with altitude is slightly altered, and not in agreement with lidar-derived extinction. RH correction is thus not appropriate on this day. RH profiles were found to increase from $35 \%$ at the surface to $70 \%$ at the top of the PBL. The fact that a sharp maximum has not been observed on the aerosol extinction coefficient at the top of the PBL for 20 July suggests that aerosols in the accumulation mode are hydrophobic under $70 \%$.

As in the case of the previous days, the profile of aerosol extinction derived from the PCASP and the nephelometer measurements agree well with those measured by the lidar on 31 July. Contrary to 19 and 20 July cases, the extinction profile after Hänel's correction is in better accordance with the lidar-derived extinction coefficient. Variations in the atmospheric column may therefore be mainly related to aerosol size growth with increasing RH. It is confirmed by Chazette et al. (2005) who showed that aerosols carried by South winds on 31 July were young and hydrophilic thanks to lidar measurements noting that extinction coefficients were higher in altitude without any modification in the size distribution.

These comparisons underline the ability of our method to reproduce the evolution of aerosol properties in the PBL and, in spite of sharp variations in the atmospheric column, enable to validate the closure study previously presented. 


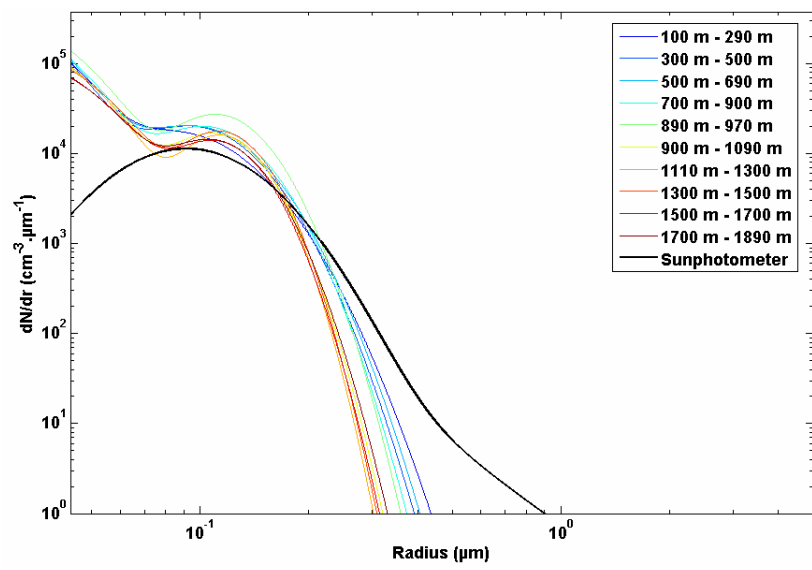

Fig. 9. Aerosol number size distribution derived from solar almucantar measurements acquired by the sun photometer over Paris area (AERONET) and size distributions measured by the PCASP at each altitude level on 31 July 2000.

\subsection{Discussion on the uncertainties}

We can firstly notice that we had chosen $n_{i} \leq 0.05$ because anthropogenic aerosols from automobile traffic do not present higher imaginary parts. AERONET retrievals discussed in Sect. 5.2 and chemical analyses reported in Sect. 5.3 have finally shown that $n_{i}$ was always lower than 0.025 in July 2000 over Paris area. The assumption we made $n_{i} \leq 0.05$ is therefore not forcing at all.

In Sect. 4, we have showed that profiles of real and imaginary parts might present very different shapes. The influence of the real part in the determination of the imaginary one has been investigated through a sensitivity analysis on the real part. As a matter of fact, an absolute error of 0.02 on the real part, which is the error calculated on our retrievals with the Monte Carlo method (Table 2), triggers off only a slight variation on the imaginary part of 0.001 in comparison with the total error of 0.003 retrieved from the Monte Carlo method (Table 2). The impact of the real part on the imaginary part of the ACRI is thus not dominating. Variations of the imaginary part in the atmospheric column can therefore be more ascribed to changes in size distribution and BER than to variations in the real part profile.

On the other hand, BER has been supposed constant with altitude for the calculation of the imaginary part and its determination $(0.014 \pm 0.0003)$ has required a synergy between lidar and sun photometer measurements according to the optical thicknesses. A BER profile taking into account $\mathrm{RH}$ can be retrieved with Eqs. (1) and (2) through a Mie code (Fig. 3). We noticed that this profile is almost constant with altitude, no noticeable peak being observed as a function of height. Mean values of $0.0137 \pm 0.0003,0.0132 \pm 0.0006$ and $0.0140 \pm 0.0006$ for 19,20 and 31 July respectively have been found, suggesting that RH correction do not introduce any bias in the calculations because uncertainties overlap in all cases. The BER calculated after RH correction is very close to the "input BER" used to invert lidar data. This result is consistent with that reported by de Leeuw et al. (1986) and Takamura and Sasano (1987) who also found that the dependence of BER on relative humidity was small. In addition it is in accordance with a previous study carried out on Paris city hall place (Raut and Chazette, 2007) showing that the BER at $355 \mathrm{~nm}$ and $532 \mathrm{~nm}$ in Paris remained almost constant (uncertainty of $5.10^{-4}$ only) for RH comprised between $40 \%$ and $80 \%$. The determination of the BER thanks to the combination lidar/sunphotometer turns out to be a prevailing actor governing the synergy between remote sensing and in situ measurements.

Nevertheless, we have to make sure that the agreement between simulated extinction profiles and lidar-derived extinction coefficient profiles really reveals the variations of physical properties in the PBL and are not affected by the "calibration" of the lidar on the sun photometer. We therefore calculated the BER independently of lidar measurements: AERONET size distributions are derived from solar almucantar data acquired over Paris area to assess the BER during this period. This step of the discussion has been included in Fig. 3. Since the retrieval algorithm produces volume size distribution integrated on the atmospheric column $\left(\mu \mathrm{m}^{3} / \mu \mathrm{m}^{2}\right)$, we used the mixed layer heights over this period, derived from lidar data, to convert the size distribution in true concentration units. The height of the PBL for each day was given in Sect. 2.2. Volume size distributions have been converted to number size distributions and are shown in Fig. 9 for 31 July, together with size distributions measured by the PCASP. Equivalent size distributions have been observed for 19 and 20 July. It can be useful to compare those size distributions. Number size distributions present two modes centered at 0.1 and $1.2 \mu \mathrm{m}$; the first mode is highly predominant with $99 \%$ of the total number of particles and is optically efficient. The first modal radius from AERONET is in accordance with the accumulation mode measured with the PCASP and presented on Table 1 with a smaller dispersion. It is now well known that AERONET is not able to manage the detection of very small particles with a radius lower than $50 \mathrm{~nm}$, whereas the sampling of coarse aerosols is a limitation of the PCASP. Such size distributions have been used as input in a Mie model, together with ACRI values retrieved from almucantar measurements (Sect. 5.2), so as to derive the BER given by the sun photometer alone. We finally found $0.0135 \pm 0.0009$, which is slightly lower that the BER used in this study $(0.014 \pm 0.0003)$ but the error bars overlap. The fine mode measured by the PCASP and coarse mode measured in AERONET stations have therefore a negligible influence on an optical ratio such as BER $(0.0135 \pm 0.0009)$. These results indicate that the value of BER used to invert lidar measurements can be determined from a set of almucantar measurements alone, instead of having recourse to the synergy between lidar and sun photometer 
measurements of optical thicknesses. It guarantees the independence of the steps in the closure study and validates our method when retrieving simulated aerosol extinction coefficients on a vertical scale in agreement with lidar-derived extinction profiles.

\section{Conclusions}

We have presented an assessment of the aerosol complex refractive index using the synergy between lidar, sunphotometer and in situ measurements during flights over Paris area in July 2000. The merit of this technique is that it provides, for the first time, vertically resolved ACRI in the PBL with a high vertical resolution of $200 \mathrm{~m}$. We showed that the main variations in the atmospheric column have to be ascribed to the geographic origin, the source and the history of the air masses carrying aerosols. Aerosols produced over Paris area have been found to present smaller values of the real part of the ACRI (1.46-1.48) than aged particles advected from Great-Britain (1.48-1.50) measured on 19 and 20 July upon arrival over Paris region and than rural aerosols over Paris area ( $>1.50)$ sampled on 31 July. But no significant tendency has been observed for the imaginary part. A good agreement has been demonstrated between the simulated extinction profiles based on the knowledge of ACRI and lidar-derived extinction profiles. Lidar reveals to be a powerful tool to constrain closure studies in the lower and middle troposphere so as to retrieve aerosol optical and physical properties, and particularly the ACRI. A modification of this crucial parameter governs changes in radiative properties of the PBL. The importance of parameter sets of physical particle properties on a vertical scale for the assessment of climate forcing by anthropogenically produced particles is highlighted by Intergovernmental Panel on Climate Change (IPCC, $2008^{1}$ ).

Acknowledgements. The airborne ESQUIF experiment was supported by the Institut National des Sciences de l'Univers (INSU) and the Commissariat à l'Energie Atomique.

Edited by: T. Garrett

\footnotetext{
${ }^{1}$ Intergovernmental Panel on Climate Control (IPCC): Climate Change 2007, the Fourth Assessment Report of the IPCC, Cambridge Univ. Press, in preparation, 2008.
}

\section{References}

Ackerman, T. P. and Toon, O. B.: Absorption of visible radiation in atmosphere containing mixtures of absorbing and non absorbing particles, Appl. Opt., 20, 3661-3667, 1981.

Anderson, B. E., Grant, W. B., Gregory, G. L., Browell, E. V., Collins, J. E., Sachse, G. W., Bagwell, D. R., Hudgins, C. H., Blake, D. R., and Blake, N. J.: Aerosols from biomass burning over the tropical South Atlantic region: distributions and impacts, J. Geophys. Res., 101, 24 117-24 137, 1996.

Angström, A.: The parameters of atmospheric turbidity, Tellus 16, 64-75, 1964.

Baumgardner, D. and Huebert, B.: The airborne aerosol inlet workshop: Meeting report, J. Aerosol Sci., 24(6), 835-846, 1993.

Bodhaine, B. A., Ahlquist, N. C., and Schnell, R. C.: Threewavelength nephelometer suitable for aircraft measurements of background aerosol scattering coefficient, Atmos. Environ., 10, 2268-2276, 1991.

Braslau, N. and Dave, J. V.: Effects of aerosol on the transfer of solar energy through realistic model atmospheres, J. Appl. Meteorol., 12, 601-615, 1973.

Charlson, R. J. and Pilat, M. J.: Climate: the influence of aerosols, J. Appl. Meteorol., 8, 1001-1002, 1969.

Chazette, P. and Liousse, C.: A case study of optical and chemical apportionment for urban aerosols in Thessaloniki, Atmos. Environ., 35, 2497-2506, 2001.

Chazette, P.: The monsoon aerosol extinction properties at Goa during INDOEX as measured with lidar, J. Geophys. Res., 108(D6), 4187, doi:10.1029/2002JD002074, 2003.

Chazette, P., Randriamiarisoa, H., Sanak, J., Couvert, P., and Flamant, C.: Optical properties of urban aerosol from airborne and ground based in situ measurements performed during the ESQUIF program, J. Geophys. Res., 110, D02206, doi:10.1029/2004JD004810, 2005.

D’Almeida, G. A., Koepke, P., and Shettle, E. P.: Atmospheric Aerosols - Global Climatology and Radiative Characteristics, edited by: Deepak, A., Hampton, VA, USA, 561 pp., 1991.

De Leeuw, G., Kunz, G. J., and Lamberts, C. W.: Humidity effects on the backscattering/extinction ratio, Appl. Opt., 25(22), 39713973, 1986.

Dubovik, O., Smirnov, A., Holben, B. N., King, M. D., Kaufman, Y. J., Eck, T. F., and Slutsker, I.: Accuracy assessments of aerosol optical properties retrieved from AERONET sun and sky-radiance measurements, J. Geophys. Res., 105, 9791-9806, 2000.

Dubovik, O., Holben, B. N., Eck, T. F., Smirnov, A., Kaufman, Y. J., King, M. D., Tanre, D., and Slutsker, I.: Variability of absorption and optical properties of key aerosol types observed in worldwide locations, J. Atmos. Sci., 59, 590-608, 2002.

Dye J. E. and Baumgardner, D.: Evaluation of the forward scattering spectrometer probe: I. Electronic and optical studies, J. Atmos. Ocean. Tech., 1, 329-344, 1984.

Ebert, M., Weinbruch, S., Hoffmann, P., and Ortner, H. M.: The chemical composition and complex refractive index of rural and urban influenced aerosols determined by individual particle analysis, Atmos. Environ., 38, 6531-6545, 2004.

Faxvog, F. R. and Roessler, D. M.: Carbon aerosol visibility vs particle size distribution, Appl. Opt., 17, 2612-2616, 1978.

Ferrare, R. A., Melfi, S. H., Whiteman, D. N., Poellot, M., and Kaufman, Y. J.: Raman lidar measurements of aerosol extinc- 
tion and backscattering, 2. Derivations of aerosol real refractive index, single-scattering albedo, and humification factor using a Raman lidar and aircraft size distribution measurements, J. Geophys. Res., 103, 19673-19689, 1998.

Flamant, C., Pelon, J., Chazette, P., Trouillet, V., Quinn, P. K., Frouin, R., Bruneau, D., Leon, J. F., Bates, T. S., Johnson, J., Livingston, J.: Airborne lidar measurements of aerosol spatial distribution and optical properties over the Atlantic Ocean during a European pollution outbreak of ACE-2, Tellus B, 52, 2, 662-677, 2000.

Hänel, G.: The properties of atmospheric aerosol particles as functions of the Relative humidity at thermodynamic equilibrium with the surrounding moist air, Adv. Geophys., 19, 73-188, 1976.

Haywood J., Francis, P., Osborne, S., Glew, M., Loeb, N., Highwood, E., Tanré, D., Myhre, G., Formenti, P., and Hirst, E.: Radiative properties and direct radiative effect of Saharan dust measured by the c-130 aircraft during shade: Solar spectrum, J. Geophys. Res., 108(D18), 8577, doi:10.1029/2002jd002687, 2003.

Hodzic, A., Vautard, R., Chazette, P., Menut, L., and Bessagnet, B.: Aerosol chemical and optical properties over the Paris area within ESQUIF project, Atmos. Chem. Phys., 6, 3257-3280, 2006,

http://www.atmos-chem-phys.net/6/3257/2006/.

Holben, B. N., Kaufman, Y. J., Setzer, A. W., Tanre, H. D., and Ward, D. E.: Optical properties of aerosol emissions from biomass burningin the Tropics, BASE-A, in: Global Biomass Burning, edited by: Levine, J. S., MIT Press, Cambridge, MA, 403-411, 1991.

Holben, B. N., Eck, T. F., Slutsker, I., et al.: AERONET - A federated instrument network and data archive for aerosol characterisation, Remote Sens. Environ., 66, 1-16, 1998.

Horvath, H.: Influence of atmospheric aerosols upon the global radiation balance: Atmospheric particles, in: IUPAC series on analytical and physical chemistry of environmental systems, 5, edited by: Harrison, R. M. and Van Gieken, R., Wiley, NewYork, 1998.

Jacobson, M. J.: A physically-based treatment of elemental carbon optics: implications for global direct forcing of aerosols, Geophys. Res. Let., 27(2), 210-220, 2000.

Katrinak, K. A., Rez, P., Perkes, R., and Busek, P. R.: Fractal geometry of carbonaceous aggregates from an urban aerosol, Environ. Sci. Technol., 24, 539-547, 1993.

Lenoble, J.: Atmospheric Radiative Transfer, edited by: Deepak, A., Hampton VA, USA, 532 pp., 1993.

Liousse, C., Devaux, C., Dulac, F., and Cacheir, H.: Aging of Savanna biomass burning aerosols: consequences for their optical properties, J. Atmos. Chem., 22, 1-17, 1995.

Lurmann, F. W., Wexler, A. S., Pandis, S. N., Musarra, S., Kumar, N., and Seinfeld, J. H.: Modeling urban and regional aerosols: II. Application to California's South coast air basin, Atmos. Environ., 31, 2695-2715, 1997.

Menut, L., Vautard, R., Flamant, C., et al.: Measurements and modelling of atmospheric pollution over the Paris area: An overview of the ESQUIF project, Ann. Geophys., 18, 1467-1481, 2000, http://www.ann-geophys.net/18/1467/2000/.

Method, T. J. and Carlson, T. N.: Radiative heating rates and some optical properties of the St. Louis aerosol as inferred from aircraft measurements, Atmos. Environ., 16, 53-66, 1982.

Müller, D., Wandinger, U., and Ansmann, A: Microphysical particle parameters from extinction and backscatter lidar data by inversion with regularization: Theory, Appl. Opt., 38, 2346-2357, 1999.

Müller, D., Ansmann, A., Wagner, F., Franke, K., and Althausen, D.: European pollution outbreaks during ACE 2: Microphysical particle properties and single-scattering albedo inferred from multiwavelength lidar observations, J. Geophys. Res, 107(D15), 4248, doi:10.1029/2001JD001110, 2002.

Pandis, S. N., Wexler, A. S., and Seinfeld, J. H.: Dynamics of tropospheric aerosols, J. Phys. Chem., 99, 9646-9659, 1995.

Pelon J., Flamant, C., Chazette, P., Leon, J. F., Tanré, D., Sicard, M., and Satheesh, S. K.: Characterization of aerosol spatial distribution and optical properties over the Indian Ocean from airborne LIDAR and radiometry during INDOEX'99', J. Geophys. Res., 107(D19), 8029, doi:10.1029/2001JD000402, 2002.

Pruppacher, H. R. and Klett, J. D.: Microphysics of clouds and precipitation, Kluwer Academic, Dordrecht, 1997.

Randriamiarisoa, H., Chazette, P., Couvert, P., Sanak, J., and Mégie, G.: Relative humidity impact on aerosol parameters in a Paris suburban area, Atmos. Chem. Phys., 6, 1389-1407, 2006, http://www.atmos-chem-phys.net/6/1389/2006/.

Raut, J.-C. and Chazette, P.: Retrieval of aerosol complex refractive index from a synergy between lidar, sunphotometer and in situ measurements during LISAIR experiment, Atmos. Chem. Phys., 7, 2797-2815, 2007, http://www.atmos-chem-phys.net/7/2797/2007/.

Redemann, J., Turco, R.P., Liou, K. N., Russell, P. B., Bergstrom, R. W., Schmid, B., Livingston, J. M., Hobbs, P. V., Hartley, W. S., Ismail, S., Ferrare, R. A., and Browell, E. V.: Retrieving the vertical structure of the effective aerosol complex index of refraction from a combination of aerosol in situ and remote sensing measurements during TARFOX, J. Geophys. Res., 105(D8), 9949-9970, 2000.

Shettle, E. P. and Fenn, R. W.: Models for the Aerosols of the Lower Atmosphere and the Effects of Humidity Variations on their Optical Properties, Project 7670, Air Force Geoph. Lab., Massachusetts, 1979.

Sinyuk, A., Torres, O., and Dubovik, O.: Combined use of satellite and surface observations to infer the imaginary part of refractive index of Saharan dust, Geophys. Res. Lett., 30(2), 1081, doi:10.1029/2002GL016189, 2003.

Sloane, C. S.: Optical properties of aerosols of mixed composition, Atmos. Environ., 18, 871-878, 1984.

Strapp, J. W., Leaitch, W. R., and Liu, P. S. K.: Hydrated and dried aerosol size distribution measurements from the particle measuring systems FSSP-300 probe and the deiced PCASP-100X probe, J. Atmos. Oceanic Technol., 9, 548-555, 1992.

Takamura, T. and Sasano, Y.: Ratio of aerosol backscatter to extinction coefficients as determined from angular scattering measurements for use in atmospheric lidar applications, Opt. Quant. Electron., 19, 293-302, 1987.

Tegen, I. and Fung, I.: Contribution to the atmospheric mineral aerosol load from land surface modification, J. Geophys. Res., 100, 18 707-18 726, 1995.

Todd, M. C., Washington, R., Martins, J. V., Dubovik, O., Lizcano, G., M'Bainayel, S., and Engelstaedter, S.: Mineral dust emission from the Bodélé Depression, Northern 
Chad, during BoDEx 2005, J. Geophys. Res., 112, D06207, doi:10.1029/2006JD007170, 2007.

Volz, F. E.: Infrared Optical Constants of Ammonium Sulfate, Sahara Dust, Volcanic Pumice, and Fly ash, Appl. Opt., 12, 564568, 1973.

Von Hoyningen-Huene, W., Schmidt, T., Chan, A. K., Heintzenberg, J., Neusuess, C.: Climate-relevant aerosol parameters of South-East Asian forest fire haze, J. Aerosol Sci., 29, 1259-1260, 1998.
Wagner, F., Müller, D., and Ansmann, A.: Comparison of the radiative impact of aerosols derived from vertically resolved (lidar) and vertically integrated (Sun photometer) measurements: Example of an Indian aerosol plume, J. Geophys. Res, 106(D19), 22 861-22 870, doi:0148-0227/01/2001JD00032, 2001.

Zobel, R. F.: Temperature and humidity changes in the lowest few thousand feet of the atmosphere during a fine summer day in southern England, Q. J. Roy. Meteor. Soc., 92, 196-209, 1966. 